\title{
Predictors of longitudinal cognitive ageing from age 70 to 82 including $A P O E$ e4 status, early-life and lifestyle factors
}

\author{
${ }^{\square}$ Janie Corley $\mathrm{PhD}^{1}$, Federica Conte $\mathrm{PhD}^{2}$, Sarah E. Harris $\mathrm{PhD}^{1}$, Adele M. Taylor MA ${ }^{1}$, \\ Paul Redmond BSc ${ }^{1}$, Tom C. Russ $\mathrm{PhD}^{1,3}$, Ian J. Deary $\mathrm{PhD}^{*}{ }^{1}$, Simon R. Cox PhD* \\ ${ }^{1}$ Lothian Birth Cohorts, Department of Psychology, University of Edinburgh, UK \\ ${ }^{2}$ Department of Psychology, University of Milano-Bicocca, Milan, IT \\ ${ }^{3}$ Alzheimer Scotland Dementia Research Centre, University of Edinburgh, UK \\ *Authors contributed equally
}

${ }^{\square}$ corresponding author:

Dr Janie Corley, Lothian Birth Cohorts, Department of Psychology, University of Edinburgh, 7 George Square, Edinburgh, UK, EH8 9JZ. Email: Janie.Corley@ed.ac.uk

\begin{abstract}
Discovering why some people's cognitive abilities decline more than others is a key challenge for cognitive ageing research. The most effective strategy may be to address multiple risk factors from across the life-course simultaneously in relation to robust longitudinal cognitive data. We conducted a 12-year follow-up of 1091 (at age 70) men and women from the longitudinal Lothian Birth Cohort 1936 study. Comprehensive repeated cognitive measures of visuospatial ability, processing speed, memory, verbal ability, and a general cognitive factor, were collected over five assessments (age 70, 73, 76, 79, and 82 years) and analysed using multivariate latent growth curve modelling. Fifteen life-course variables were used to predict variation in cognitive ability levels at age 70 and cognitive slopes from age 70 to 82 . Only APOE e4 carrier status was found to be reliably informative of general- and domainspecific cognitive decline, despite there being many life-course correlates of cognitive level at age 70 . $A P O E$ e 4 carriers had significantly steeper slopes across all three fluid cognitive domains compared with non-carriers, especially for memory $(\beta=-0.234, \mathrm{P}<0.001)$ and general cognitive function $(\beta=$ $-0.246, \mathrm{P}<0.001)$, denoting a widening gap in cognitive functioning with increasing age. Our findings suggest that when many other candidate predictors of cognitive ageing slope are entered en masse, their unique contributions account for relatively small proportions of variance, beyond variation in $A P O E$ e 4 status. We conclude that $A P O E$ e4 status is important for identifying those at greater risk for accelerated cognitive ageing, even among ostensibly healthy individuals.
\end{abstract}




\section{Introduction}

With advancing age, a pattern of decline is observed across a multitude of cognitive domains, the magnitude differs across domains, and individual differences in rate of cognitive change are substantial [1-2]. Some cognitive abilities, such as vocabulary, remain relatively intact into later life. Other, complex cognitive processes such as processing speed, reasoning, and memory-which require the manipulating of mental data - begin to decline from early adulthood [3-5], and some of these changes are underpinned by a general factor of cognitive ageing [6-8]. Deterioration in cognitive abilities is linked to impairments in older adults' everyday functions [9], quality of life [10], and health [11], as well as spiralling healthcare costs. Better understanding of long-term cognitive trajectories and their determinants, could inform public policy regarding targeted interventions for those adults at greatest risk of rapid decline, and of progression to Alzheimer's Disease and other dementias [12], as well as protective factors for staying sharp in later life.

The determinants of individual differences in age-related cognitive decline are likely to include genetic and early-life factors, adult socio-economic status, and health [13-15], though estimates differ with respect to their individual contributions. Risk of accelerated cognitive decline increases with age, cerebrovascular disease, cardiovascular risk factors (e.g. diabetes, obesity) and heart disease [16], but these factors only partially account for cognitive decline risk among the general population [14]. The APOE (apolipoprotein) e4 allele is a well-established genetic risk factor for Alzheimer's disease [1718], however, the reported effects of $A P O E$ e 4 across the full spectrum of cognitive functioning are highly inconsistent and there is disagreement about whether or not $A P O E$ e4 influences the rate of cognitive decline in healthy adults [19-25]. Despite a broad corpus of research literature on the role of behavioural risk factors in mitigating age-related cognitive decline, such as smoking, physical activity, alcohol, and diet [3, 26-27], the evidence is patchy and often classed as low to moderate quality [10]. Importantly, many of the effect sizes are small, some are poorly replicated, and findings are often partly, or wholly, attributed to reverse causation, where prior cognitive ability causes variation in the supposed cause of cognitive ability in later adult life [13].

Cognitive decline trajectories are likely to be the result of an accumulation of small effects from numerous individual genetic and environmental risk factors across the life-course [28]. Even smoking, for which there is consistent and demonstrable evidence of an adverse effect on cognitive and brain ageing [29-31], generally accounts for around only $1 \%$ of the variance in cognitive decline, similar in magnitude to the estimated effect size of $A P O E$ e 4 on cognitive change from childhood to adulthood [32]. Given that many risk factors for cognitive decline are correlated [33], modelling these potential predictors together, i.e. simultaneously, may be a more useful approach than focussing on single candidate determinants (such as one individual lifestyle or health factor). Multivariate modelling acknowledges the multicollinearity among risk factors and provides more insight into their relative 
contributions to cognitive change. The very few studies to have tested multiple risk factor models of longitudinal (multi-domain) cognitive decline report few consistent correlates of cognitive change across abilities [34-35]. In the same sample as in the current study - the Lothian Birth Cohort 1936-an earlier multivariate analysis by Ritchie et al. showed that faster rates of decline from age 70 to 76 years were observed in $A P O E$ e 4 carriers, men, and those with poorer physical fitness for some, but not all, cognitive domains [36]. The present study doubles the time frame of that paper (from six to twelve years of follow up), using data from five sampling occasions over a more critical period for accelerated cognitive decline and dementia [37-38], and includes several additional potential predictors (depression, living alone, physical activity, stroke). Having previously identified $A P O E$ e4 status as an independent predictor of cognitive change in this cohort and elsewhere, we also perform separate trajectory analyses by $A P O E$ e 4 status.

A major challenge in understanding the predictors of cognitive ageing trajectories is the difficulty in disentangling actual cognitive change from lifelong levels of performance (which are conflated in crosssectional data) and partitioning the variance appropriately [8]. Longitudinal studies with years of repeated cognitive measures are key to understanding the dynamics of cognitive change as people age and can thereby suggest how outcomes might be linked to putative influences. Studies with longer sampling periods and multiple observations increase the power to detect reliable effects and provide more robust evidence than those with few measurement points [15]. Good characterisation of cognitive abilities is crucial, using several cognitive tests for each domain which are sensitive to subtle, agerelated, cognitive changes. The accurate estimation of slope trajectories also requires appropriate statistical methods which take into account the complexity of longitudinal, observational data.

Here, we apply multivariate latent growth curve modelling to comprehensive cognitive data collected at five time-points over 12 years to characterise trajectories of cognitive change from ages 70 to 82 , and their determinants, in a sample of community-dwelling older adults living in Scotland-the Lothian Birth Cohort 1936 (LBC1936) — for whom there are cognitive function scores from early life. Studies that can account for early-life cognitive ability are rare and valuable with respect to the temporal primacy of cognitive changes (see Box 1 for other advantages of the study design). Trajectories of cognitive function were evaluated for four major domains of cognitive ability-visuospatial ability, processing speed, and memory (characterising fluid intelligence), and verbal ability (characterising crystallized intelligence). A wide range of potential predictors of cognitive decline from the previous literature were selected covering several categories: early-life (education, childhood IQ); demographic (age, sex, living alone, socio-economic status); lifestyle (smoking, physical activity, body mass index, alcohol), health (cardiovascular disease, diabetes, stroke); depressive symptoms; and APOE e4 carrier status. We also examine associations between predictors and a general factor of cognitive function which accounts for the shared variance across the cognitive domains. 


\section{Materials and Methods}

\section{Participants}

The Lothian Birth Cohort 1936 (LBC1936) [39-41] is a community-dwelling sample of 1091 men and women in Scotland, being studied in later life for the purposes of assessing the nature and determinants of cognitive and brain ageing, for whom childhood IQ scores are available. Participants were recruited into the LBC1936 in 2004-2007 at the age of $~ 70$ years, and have so far been followed-up every three years at ages $73(\mathrm{~N}=866), 76(\mathrm{~N}=697), 79(\mathrm{~N}=550)$, and $82(\mathrm{~N}=431)$. Socio-demographic, medical history, physical function, blood-derived biomarkers, cognitive function, and lifestyle data were collected at all five waves of in-person testing. For the purposes of the current study, 'completers' refer to participants who remained in the study at the age 82 assessment $(\mathrm{N}=431)$, and non-completers $(\mathrm{N}=$ 660 ) were those who dropped out or died at any point between baseline testing and age 82 follow-up. The LBC1936 are surviving participants of the Scottish Mental Survey of 1947 (SMS1947), which tested the mental ability of 70,805 11-year old children born in 1936, using a general intelligence test (The Moray House Test (MHT)) [42]. MHT scores were recorded and archived by the Scottish Council for Research in Education (SCRE), and were made available to the LBC1936 study. For the current study, the MHT score from age 11 was age corrected and converted into a standard IQ-type score for the sample (mean $=100, \mathrm{SD}=15$ ) —henceforth referred to as age $11 \mathrm{IQ}$ - and used a measure of childhood cognitive ability.

Ethical approval. Ethical approval was obtained from the Multicentre Research Ethics Committee for Scotland (baseline, MREC/01/0/56), the Lothian Research Ethics Committee (age 70, LREC/2003/2/29), and the Scotland A Research Ethics Committee (ages 73, 76, 79, 82, 07/MRE00/58). All participants provided written informed consent.

\section{Cognitive Measures}

Cognitive function was measured using a detailed battery of well-validated cognitive tests administered at age 70 (baseline), and repeated at ages 73, 76, 79, and 82 years, by trained psychologists [39]. Most of the cognitive tests derive from the Wechsler Adult Intelligence Scale III-UK edition [43] and the Wechsler Memory Scale III-UK edition (WMS-IIIUK) [44]. According to previous work examining their correlational structure [7], the cognitive tests were categorised into four domains of cognitive functioning. Visuospatial ability was measured using Block Design and Matrix Reasoning (WAISIIIUK) and Spatial Span (Forwards and Backward) (WMS-IIIUK). Processing Speed was measured using Digit-symbol Coding and Symbol Search (WAISIII-UK) and two experimental tasks: Choice Reaction Time [45]; and Inspection Time [46]. Memory was measured using Verbal Paired Associates and Logical Memory (WMSIII-UK) and Digit-span Backwards (WAIS-IIIUK). Verbal ability was measured using the National Adult Reading Test [47], the Wechsler Test of Adult Reading [48], and 
medRxiv preprint doi: https://doi.org/10.1101/2022.02.25.22271448; this version posted February 26, 2022. The copyright holder for this preprint

(which was not certified by peer review) is the author/funder, who has granted medRxiv a license to display the preprint in perpetuity.

It is made available under a CC-BY-ND 4.0 International license .

PREDICTORS OF LONGITUDINAL COGNITIVE AGEING...

Verbal Fluency [49]. A general cognitive factor was constructed based on the shared variance between the four cognitive domains (see Statistical Analysis). The Mini-Mental State Examination (MMSE) [50], widely used as a screening test for possible dementia, was administered at each wave of testing.

\section{Predictor Measures}

Potential risk or protective factors for cognitive decline in later life were identified following a review of previous analyses of the cohort and other population studies; values were obtained from participants' baseline assessment at age 70 .

Demographics and early-life. These predictors included age (in days), sex, age 11 IQ score (described above), education (years of formal full-time schooling), living alone (yes/no), and socioeconomic status (SES). SES was coded into six categories based on participants' highest achieved occupation: 1 (highest professional occupations) to 5 (unskilled occupations), with 3 (skilled occupations) divided into $3 \mathrm{~N}$ (non-manual) and 3M (manual), using the Classification of Occupations, 1980 [51].

Lifestyle. Smoking was coded as current, former or never smoker. Physical activity was coded according to six categories: 1 ('moving only in accordance with household chores'; lowest level of activity) to 6 ('keep fit or aerobic exercise several times a week'; highest level of activity). Alcohol units per week were calculated using data collected at interview. Body mass index was calculated using height and weight measurements taken by trained nurses at the time of assessment. Depressive symptoms were measured using the Depression subscale of the Hospital Anxiety and Depression Scale [52] with a score range of 0-21.

APOE $\mathrm{e} 4$ and health indicators. $A P O E$ e 4 carrier status (yes/no) was determined by genotyping at two polymorphic sites (rs7412 and rs429358) using TaqMan technology. Health indicators included self-reported history (yes/no) of cardiovascular disease (CVD), diabetes, and stroke.

\section{Statistical Analysis}

Descriptive. Descriptive statistics are presented for the full sample, and ANOVA and Chi-square tests were used to identify differences in baseline characteristics between groups (completers vs noncompleters and deaths vs non-deaths).

Trajectories of cognitive decline. We applied latent growth curve (LGC) modelling to the data to investigate level (i.e. intercept, age 70) and trajectories of change (i.e. slope, age 70 to 82) in cognitive functioning across all five waves of testing. A SEM-based 'factor-of-curves' [53] approach was used, as has been done previously in this cohort $[36,54]$ which postulates the existence of common latent variables of cognitive change that underlie the distribution of explicit or observable variables (individual cognitive tests). In our models, we used the average time lag (in years) between the waves: 
$(0,2.98,6.75,9.81,12.53)$ as the path weights for calculation of the slope factor. The path from the slope factor to baseline test score was set to zero. ${ }^{1}$ LGC analyses were conducted using the latent variable analysis package 'lavaan' [55] in R version 4.0.2 (R Foundation for Statistical Computing, Vienna, Austria) and the code is available online (https://www.ed.ac.uk/lothian-birthcohorts/discoveries/summary-data-resources). First, we fitted a single parallel process growth curve model at the level of the thirteen individual cognitive tests; intercepts and slopes were correlated, but no hierarchical factor structure was imposed. Second, we fit separate growth curve models for each cognitive domain: visuospatial ability; processing speed; memory; and verbal ability. Here, the latent intercepts and slopes of each cognitive test load onto superordinate latent intercepts and latent slopes of their respective cognitive domains. The cognitive domain models were run for the full sample and also by $A P O E$ e 4 carrier status (yes/no). Unstandardized (beta) estimates, standard errors, p-values, and standard deviation (SD) change per year, are reported.

Predictors of cognitive level and slope. We fit both univariate and multivariate risk factor models to the cognitive data to address which factors might contribute to individual differences in cognitive level (age 70) and slope (age 70 to 82). First, univariate LGC models were fit to test the associations of the fifteen individual life-course predictors (alongside age and sex) with each cognitive domain, i.e. without the other variables present in the model. For our main analyses, we fit multivariable LGC models to investigate the relative contributions of each risk factor to cognitive level and slope for each cognitive domain. By including all of the predictors simultaneously, we were able to compare the degree of variance in cognitive level and change accounted for by each risk factor, whilst controlling for the effects of all the other predictors in the model. We ran an additional model representing a general cognitive factor; this hierarchical model was fitted using the latent intercepts and slopes of each of the four cognitive sub-domains, and represents the shared (common) variance between them (Figure 1 illustrates the hierarchical model framework for general cognitive function). Fully standardised estimates, obtained using the 'standardizedSolution' function in lavaan, are presented.

Gaussian confounds analysis. With a large set of predictors, as in the current study, we increase the proportion of variance that can be explained in our cognitive outcomes by chance. In order to test whether or not the variance accounted for by the real predictors was comparable to a set of random predictors, we generated a set of Gaussian noise (and random binary) variables and entered them into the LGC models in place of the real predictors, and compared the model $\mathrm{R}^{2}$ for each domain. To

\footnotetext{
${ }^{1}$ To test for non-linear components of cognitive ageing, separate measurement models included a quadratic term with quadratic increasing slope weightings. Visual inspection of the mean trajectory of memory test scores from age 70-82 indicated that memory might best be modelled using a non-linear factor of change (to account for the rise in mean test scores in the initial waves of testing, followed by a fall towards the end of the follow-up). However, these models did not converge and are not discussed further.
} 
optimise comparability, we ensured that the same number of continuous vs binary variables were used, and that the patterns of missingness were matched with the real-world predictors.

Sensitivity analyses. We repeated the same baseline prediction models in three sensitivity analyses excluding: 1) individuals who reported a subsequent-to-baseline diagnosis of dementia (all participants were dementia-free at baseline); 2) individuals with an MMSE score <24 at any wave, as an indicator of possible pathological ageing; 3 ) deaths to follow-up (using linkage data obtained via National Health Service Central Register up to April 2021, provided by the National Records of Scotland).

Model fit and significance statistics. Models were run using full information maximum likelihood (FIML) estimation to ensure models used all available data to partially mitigate the bias of estimated trajectories and associations by participation bias. Instances of non-significant negative residual variance were set to 0 to allow models to converge upon within-bounds estimates. Model fit was tested using three indices of absolute fit: Comparative Fit Index (CFI) and Tucker-Lewis Index (TLI) (values $>0.95$ considered acceptable); and Root Mean Square Error of Approximation (RMSEA) (values $<0.06$ considered acceptable). Correction for multiple testing was applied across LGC prediction models using the False Discovery Rate (FDR) [56] adjustment, and results marked in bold type are FDR-significant.

\section{Results}

\section{Descriptive}

Baseline characteristics and cognitive test scores for the sample $(\mathrm{N}=1091)$ are shown in Table 1. Baseline age was 70 years (mean $=69.5, \mathrm{SD}=0.8), 49.8 \%$ of the sample were women, and mean number of years of education was 10.7 ( $\mathrm{SD}=1.1)$. APOE e4 allele carriers $(\mathrm{N}=306)$ made up $28.0 \%$ of the overall sample. APOE e4 data were missing for 63 participants (5.8\% of the sample). Characteristics are also presented according to completer status, and mortality status by the end of the follow-up period. Participants with fewer follow-up examinations (i.e. non-completers, $\mathrm{N}=660$ ) had less education, lower childhood IQ, lower SES, lower physical activity, higher BMI, more depressive symptoms, and were more likely to be a smoker, have a history of CVD, diabetes, and stroke. Noncompleters had significantly lower cognitive test scores at baseline than completers. Participants lost to follow-up as a result of death $(\mathrm{N}=403)$ had a lower age $11 \mathrm{IQ}$, lower SES, lower physical activity, higher BMI, higher alcohol intake, more depressive symptoms, and were more likely to be male, a smoker and to have a medical history of CVD, diabetes and stroke, than those who survived to followup. Mean cognitive test scores at baseline were significantly lower in those who had died, compared with the survivors, except for Verbal Pairs (a memory test) and Verbal Fluency (a verbal ability test), for which the group differences were not significant. As noted above, we used FIML estimation in our LGC analyses to reduce any bias due to missingness. 
A summary of the longitudinal cognitive test scores for the whole sample is presented in Table 2. Mean cognitive test scores declined between age 70-baseline and age 82 follow-up, except for two memory tests (Logical Memory and Verbal Pairs) and the verbal ability tests (NART, WTAR, and Verbal Fluency), which were marginally higher at age 82. Logical Memory and Verbal Pairs contain memorable material, which may have resulted in a rise in score in at least the second occasion of testing as a result of practice effects. All three verbal ability tests showed little change over time, and small increases in mean scores at age 82 compared with baseline. Further descriptive information about the cognitive tests scores for completers only, and by $A P O E$ e 4 carrier status, is provided in the Supplementary materials. In the subset of completers only (Supplementary Table S1; this has the advantage that the same individuals appear at all waves), all of the mean cognitive test scores were lower at age 82 follow-up compared with baseline with the exception of WTAR (where the mean score was the same), and NART and Verbal Fluency which were slightly higher at follow-up. Note that Choice Reaction Time is scored negatively, such that a higher score indicates a slower reaction time. Mean cognitive test scores at age 70 and age 82 differed according to $A P O E$ e 4 carrier status (Supplementary Table S2). At age 70, APOE e4 carriers had significantly lower scores on Matrix Reasoning, Spatial Span and Inspection Time than non-carriers. By age 82, APOE e4 carriers had significantly lower scores on Block Design, Matrix Reasoning, Spatial Span, Digit-symbol Coding, Symbol Search, Choice Reaction Time, Logical Memory, Verbal Pairs, and Digits Backwards, and the differences were larger in magnitude than at age 70. Figure 2 plots the linear fitted regression lines through the raw test data for each of the cognitive tests by APOE e4 carrier status (non-linear fitted lines through the same data can be found in Supplementary Figure 1).

\section{Trajectories of cognitive decline}

Individual cognitive test scores. First, we simultaneously tested whether there was significant ageing-related mean change in each of the thirteen individual cognitive tests in a single parallel process LGC model (Supplementary Table S3). There was a significant, negative mean slope for all tests ( $\mathrm{P}<$ 0.001 except WTAR $(\mathrm{P}<0.05)$ ), with the exception of NART where the slope was non-significant. Standard deviation (SD) change per year was calculated for each cognitive test score and ranked in order of most change (1) to least change (13). The four individual processing speed tests showed the largest SD declines over time (range, -0.120 to -0.072 ), followed by the three visuospatial tests (range, -0.055 to -0.038 ), the three memory tests (range -0.038 to -0.027 ), and the three verbal ability tests (range, -0.010 to 0.0001 ) which showed the least decline. SD change in NART scores was marginally positive but not significantly different from zero $(\mathrm{SD}$ change/yr $=0.0001)$. Model fit indices for Table 3 are shown in Supplementary Table S4, alongside those for Tables 4 and 5.

Latent cognitive domains. Second, we tested whether there was significant ageing-related mean change in each of the four latent cognitive domains for all participants, and then separately by APOE e4 carrier status in LGC models (Table 3). In the full sample, there was a significant, negative mean slope 
of ageing-related change across all four cognitive domains. A latent variable of processing speed showed the greatest SD decline per year between age 70 and 82 (SD change/yr $=-0.088$ ), followed by visuospatial ability $(\mathrm{SD}$ change/yr $=-0.054)$, memory $(\mathrm{SD}$ change/yr $=-0.028)$, and verbal ability $(\mathrm{SD}$ change/yr $=-0.003)$.

In the $A P O E$ e4 non-carriers sub-group, the slopes, indicating negative mean change over time, were significant for processing speed (SD change/yr $=-0.068)$ and visuospatial ability $($ SD change/yr $=$ $-0.033)$ only, but there was little (and non-significant) change in memory $(-0.010)$ or verbal ability (-0.004). In the APOE e4 carrier sub-group, the mean slopes were negative and significant for all but verbal ability. Compared to the $A P O E$ e4 negative group, $A P O E$ e 4 carriers showed greater SD decline in processing speed (SD change/yr $=-0.106$ vs -0.068 ), visuospatial ability (SD change/yr $=-0.065$ vs -0.033 ), and memory ( $\mathrm{SD}$ change/yr $=-0.072 \mathrm{vs}-0.010$ ). The difference was most marked in the slope for memory; $A P O E$ e 4 carriers showed a 7-fold greater SD decline per year compared with APOE e4 non-carriers (and in the non-carrier group the slope for memory is non-significant). In contrast with the full sample and the $A P O E$ e4 non-carriers, memory decline was steeper than visuospatial ability decline in the $A P O E$ e4-positive group. Figure 3 presents horizontal bar plots illustrating the SD change/yr in each cognitive test for all participants, and in each cognitive domain for all participants, $A P O E$ e4 carriers, and $A P O E$ e 4 non-carriers. Formal tests of intercept and slope differences for $A P O E$ e 4 carriers and $A P O E$ e4 non-carriers are carried out below.

\section{Predictors of cognitive level and slope}

Univariate predictors of cognitive level and slope. First, we performed univariate analyses which regressed the intercepts and slopes at the level of each cognitive domain, and then general cognitive function, on all of the predictor variables individually. These univariate (partially-adjusted) models are distinct from the later models featuring multiple risk factors (fully-adjusted) which are the main models of interest. In the univariate models for cognitive ability level at age 70 , all of the predictors except living alone were significantly associated with scores on at least one cognitive domain (full results are shown in Supplementary Table S5). In the univariate models for cognitive slope, only APOE e4 status, alcohol, smoking, and age 11 IQ were significant predictors of decline across selected domains. $A P O E$ e 4 carriers were more likely to show decline between age 70 and age 82 in visuospatial ability ( $\beta$ $=-0.185, \mathrm{P}=0.005)$, speed $(\beta=-0.215, \mathrm{P}<0.001)$, memory $(\beta=-0.235, \mathrm{P}<0.001)$, and general cognitive ability $(\beta=-0.233, \mathrm{P}<0.001)$. Smoking was associated with more decline in verbal ability $(\beta$ $=-0.203, \mathrm{P}=0.004)$ only, and a higher alcohol intake was associated with more decline in visuospatial ability only $(\beta=-0.183, P=0.015)$. Finally, a higher childhood cognitive ability $(\beta=-0.252, P=$ 0.001 ) was associated with more decline in visuospatial ability only.

Multivariate predictors of cognitive level at age 70. Next, we ran multivariate models to simultaneously estimate the effect of multiple risk factors on cognitive level at age 70 . When all fifteen 
predictors were modelled at the same time, thirteen (not living alone or alcohol intake) made a significant contribution to the variability in cognitive ability level at age 70 (i.e. the intercept) in at least one of the cognitive domains (upper section, Table 4). Performance on all four cognitive domains and the general factor of cognitive function was associated with age (within-wave differences) (range, standardised beta $(\beta)=-0.089$ to $-0.157, \mathrm{P}<0.001$ ) and age 11 IQ (range $\beta=0.442$ to $0.668, \mathrm{P}<$ 0.001 ); age 11 IQ accounted for the most variance in cognitive level of any of the predictors, with the largest effect size $(\beta=0.668)$ for general cognitive function. Education and SES predicted performance in the general factor, and three out of four of the domains (no association between education-speed and between SES-memory), with an average ( $\beta$ ) effect size across the four domains of -0.176 and -0.123 , respectively. The directions of effects were as expected, such that individuals with better age 70 cognitive ability level were younger, had a higher childhood intelligence, were more educated, and were from more professional occupational classes. Male sex $(\beta=0.261, \mathrm{P}<0.001)$ was a predictor of better visuospatial ability level, and female sex was a predictor of better memory level $(\beta=0.121, \mathrm{P}<0.001)$, but sex was not a significant predictor of general cognitive function.

Healthy lifestyle factors were selectively associated with better cognitive ability at age 70: more physical activity ( $\beta=0.082, \mathrm{P}=0.009)$ and less smoking $(\beta=-0.095, \mathrm{P}=-0.001)$ with better processing speed. A higher BMI (a measure of obesity) was associated with a lower verbal ability ( $\beta=$ $-0.053, \mathrm{P}=0.01)$ but conversely with higher visuospatial ability $(\beta=0.084, \mathrm{P}=0.003)$. Alcohol intake did not significantly predict age 70 cognitive ability in any domain. None of the lifestyle factors measured were significantly associated with general cognitive function in the multivariate model. $A P O E$ e4 positive carrier status predicted poorer visuospatial ability $(\beta=-0.100, \mathrm{P}<0.001)$, processing speed $(\beta=-0.103, \mathrm{P}<0.001)$ and general cognitive function $(\beta=-0.056, \mathrm{P}=0.009)$ at age 70 . History of disease was associated with lower cognitive scores but not consistently across domains: CVD $(\beta=$ $-0.069, \mathrm{P}=0.013)$ and stroke $(\beta=-0.071, \mathrm{P}=0.011)$, were associated with lower processing speed, in addition to a non-FDR-significant association with diabetes $(\beta=-0.057, \mathrm{P}=0.04)$. Diabetes was associated with lower verbal ability $(\beta=-0.053, P=0.01)$ and general cognitive function $(\beta=--0.055$, $\mathrm{P}=0.01)$. Depressive symptoms were associated with lower processing speed $(\beta=-0.101, \mathrm{P}<0.001)$ and general cognitive function $(\beta=-0.066, P=0.002)$. Notably, many of the previous univariate associations between individual predictors and cognitive level at age 70 (across selected domains) became non-significant in the multivariate models.

Multivariate predictors of cognitive slope between age 70 and 82 . In contrast to cognitive level at age 70, we found that few predictors were associated with longitudinal cognitive change between age 70 and 82 (as shown in Table 4 for slope, lower section) once all fifteen predictors were entered simultaneously. APOE e4 carrier status accounted for the most variability in cognitive slopes. Possessing the $A P O E$ e4 allele was associated with significantly steeper decline in visuospatial ability $(\beta=-0.170, \mathrm{P}=0.009)$, processing speed $(\beta=-0.211, \mathrm{P}<0.001)$, memory $(\beta=-0.234, \mathrm{P}<0.001)$, 
and general cognitive function $(\beta=-0.246, \mathrm{P}<0.001)$, but not with verbal ability $(\beta=-0.058, \mathrm{P}=$ 0.35). Moreover, $A P O E$ e4 was the only unique significant predictor of cognitive change in processing speed, memory, and general cognitive function, with resultant effect sizes markedly larger in magnitude than any of the other variables. Other than being an $A P O E$ e 4 allele carrier, a steeper slope in visuospatial ability was also associated with a having a higher age 11 IQ $(\beta=-0.272, \mathrm{P}<0.001)$. The only predictors of a steeper verbal ability slope were more smoking $(\beta=-0.192, \mathrm{P}=0.007)$, and contrary to expectations, a lower age $(\beta=0.262, \mathrm{P}<0.001)$. Comparisons between the univariate and multivariate predictor models for cognitive slope indicate that the univariate association between higher alcohol intake and greater decline in visuospatial ability $(\beta=-0.183, P=0.015)$ was non-significant in the multivariate model $(\beta=-0.146, \mathrm{P}=0.05)$.

Figure 4 illustrates the unique variance $\left(R^{2}\right)$ accounted for by the fifteen predictor variables in Table 4 for each cognitive domain, versus a matched set of simulated random variables. These comparisons allow us to check whether our predictor group performed better than the same number of null variables, and are presented as stacked barplots showing the real data (in colour) and random data (in grey). The overall $\mathrm{R}^{2}$ for the set of real predictors was significantly larger than the null scenario across the domains: visuospatial ability (real $=20 \%$, null $=4 \%$ ); processing speed (real $8 \%=$ null $=2 \%$ ); memory $($ real $=8 \%$, null $=1 \%)$; verbal ability $($ real $=16 \%$, null $=4 \%)$; general cognitive function $($ real $=9 \%$, null $=2 \%)$.

Sensitivity analyses. We performed three sensitivity analyses to determine whether our results were driven by: participants who developed dementia by the age 82 assessment $(\mathrm{N}=24)$; low MMSE scorers at one or more testing waves $(\mathrm{N}=46)$; and deaths $(\mathrm{N}=403)$. We found no substantive differences between the results of the sensitivity analyses (reported in Supplementary Material Tables S6-8) and those reported above. The only notable result of these exclusions was an attenuation in effect sizes for the $A P O E$ e 4 associations with visuospatial ability slope, of $46 \%, 22 \%$, and $34 \%$, respectively, across the three analyses, which were no longer significant at $\mathrm{P}<0.05$.

\section{Discussion}

We characterised longitudinal changes across major domains of cognitive functioning over a 12-year period, modelling a comprehensive set of cognitive tests administered five times at 3-yearly intervalsallowing a robust examination of rates of decline-in a birth cohort of older adults for whom childhood IQ scores are available. Using a multivariate approach, we examined the relative contributions of determinants of individual differences in age 70-cognitive level and age 70 to 82-cognitive change, using fifteen of the most commonly used candidate risk factors in the field of cognitive ageing. Our key finding is that $A P O E$ e4 status was the single most important factor determining longitudinal cognitive decline when all of the predictors were modelled simultaneously. Carriers of the APOE e4 allele show 
significantly steeper declines across the three 'fluid' domains of memory, processing speed, and visuospatial ability, compared to non-carriers, even after adjusting for many other potential predictors which were strong correlates of age 70 cognitive level (including childhood IQ, education, adult socioeconomic status, lifestyle, and health). APOE e4 status was the sole predictor of decline in general cognitive function — with a moderate to large effect size of 0.25 [57] — comparable in magnitude, for instance, to the reduction in risk of dying from head injuries associated with wearing a cycling helmet [58]. This contrasts with the relatively modest cross-sectional associations between APOE e 4 and cognitive functioning at age 70 which suggests that the effect of $A P O E \mathrm{e} 4$ on cognitive deficits becomes more manifest in later life. These findings are striking given that when many other candidate predictors of cognitive ageing slope are entered en masse, their unique contributions account for relatively small proportions of variance, beyond variation in $A P O E$ e4 status, and might indicate an increasing genetic influence on cognitive outcomes as individuals' progress into their eighth and ninth decades of life.

The presence of faster rates of decline in $A P O E$ e 4 carriers, across several different domains of cognitive functioning, adds valuable new data to the debate on whether $A P O E$ e4 influences cognitive ageing. Our findings stand in contrast with some studies which report null findings such as the Australian PATH study [59], and the HALCyon programme which provided only very limited evidence of an effect of $A P O E \mathrm{e} 4$ on a test of word recall, but not on other cognitive measures [19].

Discrepancies in findings may reflect differences in sample age; both samples were considerably younger than the present study, perhaps too young to show e4-related decrements. Our results extend prior work that does find an effect of $A P O E$ e 4 in the following ways. First, we report that $A P O E$ e 4 exerts broad and general adverse effects on cognitive functioning, typically only reported in crosssectional meta-analytic data across many piecemeal studies [25], but not in a single longitudinal cohort study. Second, we found a particularly deleterious effect of $A P O E$ e 4 on memory decline, consistent with two single-candidate studies using a single memory test $[23,60]$. Here, we show this effect is robust to simultaneous adjustments in a multi-candidate study, and reliable across a broad cognitive trait of memory, captured by the latent domain. Third, we show that the relationship between APOE e4 and long-term cognitive decline is largely independent of childhood cognitive ability, an important confound (but rarely available measure) in studies of cognitive ageing [61]. Fourth, we were able to show that the $A P O E$ e 4 allele affects age-related cognitive decline independently of possible cognitive impairment, dementia, and deaths to follow up, suggesting that this relationship is present, not just in dementia and Alzheimer's Disease [17, 62], but in cognitively 'healthy' individuals.

Our results suggest that differences in cognitive functioning between e4 and non-e 4 carriers become more pronounced with advancing age, regardless of any pathological changes. This finding aligns with earlier reports of an age effect of $A P O E$ e 4 on cognition across the lifespan in single-determinant studies, with associations rarely seen in those < 70 years $[19,23]$. In 19,594 participants of the Health 
and Retirement study, age-stratified analyses showed there was relatively no effect of being a carrier at age 50-59, compared to age 80 and above, where there was an almost 2.5 year difference in 'cognitive age', a marker of cognitive functioning, compared with non-carriers [63]. Age effects of the APOE e4 allele support theories suggesting that the presence of the allele leads to reductions in neural protection and repair, and that carriers are more vulnerable to damage accumulated over their lifetime [64].

We found limited evidence in the LBC1936 that individual health behaviours alter rates of decline between ages 70-82 years when modelled in tandem. Those with a history of smoking showed faster declines in verbal ability, in agreement with a large body of evidence documenting the detrimental effects of smoking on cognition and brain health [27, 29-30], though the change in this crystallised domain was minimal over time. One major question for the field of cognitive ageing is whether various lifestyle choices all compete for a limited opportunity to enhance cognitive function or whether the effects could be additive, as part of a synergistic lifestyle pattern [65-66]. While there were few individual effects, Figure 4 makes it clear that together, lifestyle predictors account for a greater amount of the variance in cognitive decline than might be attributed to chance. In accordance with a 'marginal gains' theory of cognitive ageing [28], individual differences in cognitive trajectories among our sample, probably reflect an accumulation of small influences from numerous lifestyle (and other) factors. Though the magnitude of the observed associations between the various individual lifestyle factors and cognitive change were mostly small, if these associations represent a causal effect, their cumulative efforts are likely to have significance for cognitive health at the population level.

Consistent with previous studies [36, 67], a higher childhood IQ — the strongest predictor of higher (cross-sectional) age-70 cognitive level in our sample—did not confer an advantage in terms of protection from steeper declines in the long-term. The only evidence of an effect of early-life cognitive ability was a faster decline in visuospatial ability in those with a higher childhood IQ. This counterintuitive finding was surprising but not unusual, and may indicate regression to the mean, that is, a consequence of higher ability individuals performing relatively more poorly on tests with known ceiling effects when followed longitudinally [68]. Nevertheless, the current study benefits from knowing individuals' cognitive starting point. Early-life cognition is associated with a subsequent cascade of social, behavioural and clinical effects [69] such that children with higher cognitive ability tend to become brighter and healthier adults [28]. Being able to remove this confound from our models is important to reduce the likelihood of the observed associations being artefacts of the relationship between childhood IQ and healthy life markers. In doing so, our findings help to address an important issue in cognitive ageing research, namely, distinguishing differential preservation from preserved differentiation $[8,70]$. With the clear exception of $A P O E$, our results support the preserved differentiation of cognitive function only — whereby level of ability is a manifestation of prior abilitybut not differential preservation (which leads to differences in subsequent rates of decline). 
Declines in processing speed between age 70 and 82 were greater than those of the other domains which supports the theory that processing speed is the core issue responsible for deficits in performance on complex cognitive measures in ageing populations [71-73]. Memory declined less steeply, across the whole sample, than processing speed and visuospatial ability, even in the ninth decade when one might expect to see more pronounced changes in this domain [74]. However, memory tests repeated longitudinally are subject to practice effects, such that participants may be able to improve or maintain their tests scores in spite of a cognitive decline [75]. Despite the potential of practice effects to obscure the variance in memory performance measured over time (e.g. in tests containing memorable information in stories or word lists), ageing effects were still present in the data, and if anything, they may lead to an underestimation of true effect sizes. Verbal ability showed evidence of stability with age, as expected [76-78]. Nevertheless, the observation of concomitant rises in word knowledge alongside marked declines in other cognitive measures with age, is still of empirical value.

Strengths and limitations. The major strength of the LBC1936 is an unusually comprehensive cognitive battery, enabling good characterisation of cognitive domains across later life, and the ability to account for childhood cognitive ability, which is uncommon in studies of cognitive ageing. Identical tests and testing location were used at five sampling occasions over a 12 year follow-up period, covering an age-critical window in later life for accelerated cognitive decline. The multivariate design of the study addresses the multicollinearity of a range of life-course predictors. Modelling latent cognitive variables reduced the influence of potential measurement error inherent in using single cognitive tests. We further improved the robustness of our results by using FDR-adjustment for multiple associations, thereby reducing the chance of type I errors., and conducting sensitivity tests for incident dementia and death.

The study results should be interpreted with several limitations in mind. As with any longitudinal study, a key limitation was survival bias such that those who remained in the study were healthier older individuals with more education, a higher SES, and a lower prevalence of comorbidities. However, the modest $20 \%$ attrition rate over each successive follow-up is comparable to those of other highly valuable longitudinal cohort studies with repeated assessments, such as the Swedish National Study on Aging [79] and the English Longitudinal Study of Ageing [80]. Using FIML in our LGC analyses partly addresses the issue of attrition by including all available data from each time-point, not just completers, resulting in less biased estimates. Some physiological processes preceding cognitive decline may occur earlier in life, therefore, mid-life measures of some risk factors, e.g. physical activity and BMI, may be more important at predicting rapid cognitive decline than measures obtained later in life [81-83], but are not available in this cohort. We were also unable to further explore associations according to APOE e4 allele variations, given that the numbers of individuals in each allele group were insufficient to conduct further comparisons between e2, e 3 and e4 genotypes. We acknowledge that our cognitive intercept at age 70 is likely to be a conflation of both intercept and some degree of slope (i.e. cognitive ageing 
medRxiv preprint doi: https://doi.org/10.1101/2022.02.25.22271448; this version posted February 26, 2022. The copyright holder for this preprint

(which was not certified by peer review) is the author/funder, who has granted medRxiv a license to display the preprint in perpetuity.

It is made available under a CC-BY-ND 4.0 International license .

PREDICTORS OF LONGITUDINAL COGNITIVE AGEING...

experienced up to that point). Without knowing individuals' mid-age (reflecting peak cognitive function) to older-age trajectories, we cannot fully address the issue of preserved differentiation vs differed preservation, though childhood IQ functions as a good proxy measure given its stability across the lifespan [84]. Finally, as a volunteer sample, the LBC1936 represent a well-educated, generally healthy group, which might preclude the generalisation of these findings to the broader ageing population, and as such, replication in other larger samples is warranted.

In summary, we found that $A P O E$ e4 status was the single most important predictor of longitudinal cognitive decline from age 70 to 82 , when fifteen potential predictors were modelled simultaneously, despite there being many life-course correlates of cognitive level at age 70. APOE e4 allele carriers experienced significantly steeper 12-year declines across the three 'fluid' domains of memory, processing speed, and visuospatial ability, and a general factor of cognitive function, than non-carriers, denoting an increasingly widening gap in cognitive functioning as individuals' progress into older age. Our findings suggest that (1) when many other candidate predictors of cognitive ageing slope are entered en masse, their unique contributions account for relatively small proportions of variance, beyond variation in $A P O E$ e4 carrier status, (2) $A P O E$ e4 status is important for identifying those a greater risk for accelerated cognitive ageing, even among ostensibly healthy individuals. 
medRxiv preprint doi: https://doi.org/10.1101/2022.02.25.22271448; this version posted February 26, 2022. The copyright holder for this preprint

(which was not certified by peer review) is the author/funder, who has granted medRxiv a license to display the preprint in perpetuity.

It is made available under a CC-BY-ND 4.0 International license.

PREDICTORS OF LONGITUDINAL COGNITIVE AGEING...

\section{Acknowledgements}

This research was funded in whole, or in part, by the Wellcome Trust [221890/Z/20/Z]. For the purpose of open access, the author has applied a CC BY public copyright licence to any Author Accepted Manuscript version arising from this submission.

We gratefully acknowledge the contributions of the LBC1936 participants and members of the LBC1936 research team who collect and manage the LBC data. We also thank the Genetics Core staff at the Edinburgh Clinical Research Facility. The LBC1936 is supported by Age UK [The Disconnected Mind], the Medical Research Council [G0701120, G1001245, MR/M01311/1, MR/R024065/1] and the University of Edinburgh. SRC and IJD were additionally supported by a National Institutes of Health (NIH) research grant R01AG054628, and IJD was also supported by the Dementias Platform UK [MR/L015382/1].SRC is supported by a Sir Henry Dale Fellowship jointly funded by the Wellcome Trust and the Royal Society (Grant Number 221890/Z/20/Z).

\section{Conflict of interest}

None 
medRxiv preprint doi: https://doi.org/10.1101/2022.02.25.22271448; this version posted February 26, 2022. The copyright holder for this preprint (which was not certified by peer review) is the author/funder, who has granted medRxiv a license to display the preprint in perpetuity.

It is made available under a CC-BY-ND 4.0 International license.

\section{References}

1. Harada CN, Love MCN, Triebel KL. Normal cognitive aging. Clin Geriatr Med 2012; 29: 737-752.

2. Salthouse TA. Trajectories of normal cognitive aging. Psychol Aging 2019; 34: 17-24.

3. Blazer DG, Yaffe K, Karlawish J. Cognitive aging: a report from the Institute of Medicine. JAMA 2015 313: 2121-2122.

4. Hedden T, Gabrieli JD. Insights into the ageing mind: a view from cognitive neuroscience. Nat Rev Neurosci 2004; 5: 87-96.

5. Salthouse TA. When does age-related cognitive decline begin? Neurobiol Aging 2009; 30: 507-551.

6. Ghisletta P, Rabbitt P, Lunn M, Lindenberger U. Two thirds of the age-based changes in fluid and crystallized intelligence, perceptual speed, and memory in adulthood are shared. Intelligence 2012; 40: $260-268$.

7. Tucker-Drob EM, Briley DA, Starr JM, Deary IJ. Structure and correlates of cognitive aging in a narrow age cohort. Psychol Aging 2014; 29: 236-249.

8. Tucker-Drob EM. Cognitive Aging and Dementia: A Life-Span Perspective. Ann Rev Dev Psychol 2019; 1: 177-196.

9. Tucker-Drob EM. Neurocognitive functions and everyday functions change together in old age. Neuropsychology 2011; 25: 368-377.

10. Plassman BL, Williams Jr JW, Burke JR, Holsinger T, Benjamin S. Systematic review: factors associated with risk for and possible prevention of cognitive decline in later life. Ann Intern Med 2010; 153: 182-193.

11. Batty GD, Deary IJ, Zaninotto P. Association of Cognitive Function With CauseSpecific Mortality in Middle and Older Age: Follow-up of Participants in the English Longitudinal Study of Ageing. Am J Epidemiol 2016; 183: 183-190.

12. Cloutier S, Chertkow H, Kergoat MJ, Gauthier S, Belleville S. Patterns of cognitive decline prior to dementia in persons with mild cognitive impairment. J Alzheimers Dis 2015; 47: 901-913.

13. Deary IJ, Corley J, Gow AJ, Harris SE, Houlihan LM, Marioni RE et al. Age-associated cognitive decline. Br Med Bul. 2009; 92: 135-152.

14. Gangolli VK. Recent advances in the understanding of cognitive decline among the elderly. $J$ Geriatr Ment Health 2016; 3: 36-43.

15. Wu Z, Phyo AZ, Al-Harbi T, Woods RL, Ryan J. Distinct cognitive trajectories in late life and associated predictors and outcomes: a systematic review. J Alzheimers Dis Rep 2020; 4: 459-478.

16. Leritz EC, McGlinchey RE, Kellison I, Rudolph JL, Milberg WP. Cardiovascular disease risk factors and cognition in the elderly. Curr Cardiovasc Risk Rep 2011; 5: 407.

17. Farrer LA, Cupples LA, Haines JL, Hyman B, Kukull WA, Mayeux R et al. Effects of age, sex, and ethnicity on the association between apolipoprotein E genotype and Alzheimer disease: a metaanalysis. JAMA 1997; 278: 1349-1356. 
medRxiv preprint doi: https://doi.org/10.1101/2022.02.25.22271448; this version posted February 26, 2022. The copyright holder for this preprint (which was not certified by peer review) is the author/funder, who has granted medRxiv a license to display the preprint in perpetuity. It is made available under a CC-BY-ND 4.0 International license .

18. Liu CC, Kanekiyo T, Xu H, Bu G. Apolipoprotein E and Alzheimer disease: risk, mechanisms and therapy. Nat Rev Neurol 2013; 9: 106-118.

19. Alfred T, Ben-Shlomo Y, Cooper R, Hardy R, Cooper C, Deary IJ et al. Associations between APOE and low-density lipoprotein cholesterol genotypes and cognitive and physical capability: the HALCyon programme. Age 2014; 36: 1-2.

20. Boyle PA, Buchman AS, Wilson RS, Kelly JF, Bennett DA. The APOE $\varepsilon 4$ allele is associated with incident mild cognitive impairment among community-dwelling older persons. Neuroepidemiol 2010; 34: 43-49.

21. Bunce D, Fratiglioni L, Small BJ, Winblad BM, Bäckman L. APOE and cognitive decline in preclinical Alzheimer disease and non-demented aging. Neurology 2004; 63: 816-821.

22. Christensen H, Batterham PJ, Mackinnon AJ, Jorm AF, Mack HA, Mather KA et al.. The association of APOE genotype and cognitive decline in interaction with risk factors in a 65-69 year old community sample. BMC Geriatr 2008; 8: 14.

23. Rawle MJ, Davis D, Bendayan R, Wong A, Kuh D, Richards M. Apolipoprotein-E (Apoe) $\varepsilon 4$ and cognitive decline over the adult life course. Transl Psychiatry 2018; 8: 1-8.

24. Schiepers OJ, Harris SE, Gow AJ, Pattie A, Brett CE, Starr JM et al. APOE E4 status predicts agerelated cognitive decline in the ninth decade: longitudinal follow-up of the Lothian Birth Cohort 1921. Mol Psych 2012; 17: 315-324.

25. Wisdom NM, Callahan JL, Hawkins KA. The effects of apolipoprotein E on non-impaired cognitive functioning: a meta-analysis. Neurobiol Aging 2011; 32: 63-74.

26. Baumgart M, Snyder HM, Carrillo MC, Fazio S, Kim H, Johns H. Summary of the evidence on modifiable risk factors for cognitive decline and dementia: A population-based perspective. Alzheimers Dement 2015; 11: 718-726.

27. Lee Y, Back JH, Kim J, Kim SH, Na DL, Cheong HK et al. Systematic review of health behavioral risks and cognitive health in older adults. Int Psychogeriatr 2010; 22: 174-187.

28. Corley J, Cox SR, Deary IJ. Healthy cognitive ageing in the Lothian Birth Cohort studies: marginal gains not magic bullet. Psychol Med 2018; 8: 187-207.

29. Anstey KJ, von Sanden C, Salim A, O'Kearney R. Smoking as a risk factor for dementia and cognitive decline: a meta-analysis of prospective studies. Am J Epidemiol. 2007; 166 :367-78.

30. Peters R, Poulter R, Warner J, Beckett N, Burch L, Bulpitt C. Smoking, dementia and cognitive decline in the elderly, a systematic review. BMC Geriatr 2008; 8: 1-7.

31. Vňuková M, Richards M, Cadar D. How do our decisions to smoke and drink in midlife affect our cognitive performance in later life? Findings from the 1946 British Birth Cohort. J Aging Geriatr Med 2017; 1: 2.

32. Deary IJ, Whalley LJ, Clair DS, Breen G, Leaper S, Lemmon H et al. The influence of the $\varepsilon 4$ allele of the apolipoprotein E gene on childhood IQ, nonverbal reasoning in old age, and lifetime cognitive change. Intelligence 2003 ; 31: 85-92. 
medRxiv preprint doi: https://doi.org/10.1101/2022.02.25.22271448; this version posted February 26, 2022. The copyright holder for this preprint (which was not certified by peer review) is the author/funder, who has granted medRxiv a license to display the preprint in perpetuity.

It is made available under a CC-BY-ND 4.0 International license.

33. Machado A, Barroso J, Molina Y, Nieto A, Díaz-Flores L, Westman E et al. Proposal for a hierarchical, multidimensional, and multivariate approach to investigate cognitive aging. Neurobiol Aging 2018; 71: 179-188.

34. Sebastiani P, Andersen SL, Sweigart B, Du M, Cosentino S, Thyagarajan B et al. Patterns of multidomain cognitive aging in participants of the Long Life Family Study. GeroScience 2020; 42 : 1335-1350.

35. Zaninotto P, Batty GD, Allerhand M, Deary IJ. Cognitive function trajectories and their determinants in older people: 8 years of follow-up in the English Longitudinal Study of Ageing. $J$ Epidemiology Community Health. 2018; 72: 685-694.

36. Ritchie SJ, Tucker-Drob EM, Cox SR et al. (2016) Predictors of ageing-related decline across multiple cognitive functions. Intelligence; 59: 115-126.

37. Prince M, Knapp M, Guerchet M, McCrone P, Prina M, Comas-Herrera A et al. Dementia UK: update. Alzheimer's Society, London, 2014.

38. Small BJ, Dixon RA, McArdle JJ. Tracking cognition-health changes from 55 to 95 years of age. $J$ Gerontol B Psychol Sci 2011; 66: i153-il61.

39. Deary IJ, Gow AJ, Taylor MD, Corley J, Brett C, Wilson V et al. The Lothian Birth Cohort 1936: a study to examine influences on cognitive ageing from age 11 to age 70 and beyond. BMC Geriatr 2007; 7: 1-2.

40. Deary IJ, Gow AJ, Pattie A, Starr JM. Cohort profile: the Lothian Birth Cohorts of 1921 and 1936. Int J Epidemiol 2012; 41: 1576-1584.

41. Taylor AM, Pattie A, Deary IJ. Cohort profile update: the Lothian Birth Cohorts of 1921 and 1936. Int J Epidemiol 2018; 47: 1042-1042r.

42. Scottish Council for Research in Education. The trend of Scottish intelligence: a comparison of the 1947 and 1932 surveys of the intelligence of eleven-year-old pupils. University of London Press: London, 1949.

43. Wechsler D. WAIS-IIIUK administration and scoring manual. Psychological Corporation: London, 1998.

44. Wechsler D. WMS-IIIUK administration and scoring manual. Psychological Corporation: London, 1998.

45. Deary IJ, Der G, Ford G. Reaction times and intelligence differences: A population-based cohort study. Intelligence 2001; 29: 389-399.

46. Deary IJ, Simonotto E, Meyer M, Marshall A, Goddard, Wardlaw J. The functional anatomy of inspection time: An event-related fMRI study. NeuroImage 2004; 22: 1466-1479.

47. Nelson HE, Willison JR. National Adult Reading Test (NART) test manual (Part II). NFER-Nelson: Windsor, England, 1991.

48. Holdnack JA. WTAR: Wechsler Test of Adult Reading manual. Psychological Corporation: San Antonio, TX, 2001. 
medRxiv preprint doi: https://doi.org/10.1101/2022.02.25.22271448; this version posted February 26, 2022. The copyright holder for this preprint (which was not certified by peer review) is the author/funder, who has granted medRxiv a license to display the preprint in perpetuity.

It is made available under a CC-BY-ND 4.0 International license .

49. Lezak MD, Howieson DB, Loring DW, Fischer JS. Neuropsychological assessment. Oxford University Press, USA, 2004

50. Folstein MF, Folstein SE, McHugh PR. "Mini-mental status". A practical method for grading the cognitive state of patients for the clinician. J Psychiatr Res 1975; 12: 189-198.

51. OPCS. Classification of Occupations 1980. HMSO: London, 1980

52. Zigmond AS, Snaith RP. The hospital anxiety and depression scale. Acta Psychiatr Scand 1983; 67: 361-370.

53. McArdle JJ. (1988). Dynamic but structural equation modeling of repeated measures data. In: Handbook of Multivariate Experimental Psychology. Springer, Boston, MA, pp. 561-614.

54. Cox SR, Harris MA, Ritchie SJ, Buchanan CR, Hernández MV, Corley J et al. Three major dimensions of human brain cortical ageing in relation to cognitive decline across the eighth decade of life. Mol Psych 2021; 26: 2651-2662.

55. Rosseel Y. lavaan: an R package for structural equation modeling. J Stat Software 2012; 48: 1-36.

56. Benjamini Y, Hochberg Y. Controlling the false discovery rate: a practical and powerful approach to multiple testing. J R Stat Soc 1995; 57: 289-300.

57. Funder DC, Ozer DJ. Evaluating effect size in psychological research: Sense and nonsense. $A d v$ Meth Pract Psychol Sci 2019; 2: 156-168.

58. Persaud N, Coleman E, Zwolakowski D, Lauwers B, Cass D. Nonuse of bicycle helmets and risk of fatal head injury: a proportional mortality, case-control study. CMAJ 2012; 184: E921-E923.

59. Bunce D, Bielak AAM, Anstey KJ, Cherbuin N, Batterham PJ, Simon Easteal. APOE Genotype and Cognitive Change in Young, Middle-Aged, and Older Adults Living in the Community. $J$ Gerontol A Biol Sci 2014; 69: 379-386.

60. Caselli RJ, Dueck AC, Osborne D, Sabbagh MN, Connor DJ, Ahern GL et al. Longitudinal modeling of age-related memory decline and the APOE $\varepsilon 4$ effect. New Eng J Med 2009: 361: 255263.

61. Deary IJ, Whiteman MC, Starr JM, Whalley LJ, Fox HC. The impact of childhood intelligence on later life: following up the Scottish mental surveys of 1932 and 1947. J Pers Soc Psychol 2004: 86: 130-147.

62. Lutz MW, Crenshaw DG, Saunders AM, Roses AD. Genetic variation at a single locus and age of onset for Alzheimer's disease. Alzheimers Dement 2010; 6: 125-131.

63. Levine ME, Harrati A, Crimmins EM. Predictors and implications of accelerated cognitive aging. Biodemography Soc Biol 2018; 64: 83-101.

64. Smith C, Graham DI, Murray LS, Stewart J, Nicoll JA. Association of APOE e4 and cerebrovascular pathology in traumatic brain injury. J Neurol Neurosurg Psychiatry 2006; 77: 363 366. 
medRxiv preprint doi: https://doi.org/10.1101/2022.02.25.22271448; this version posted February 26, 2022. The copyright holder for this preprint (which was not certified by peer review) is the author/funder, who has granted medRxiv a license to display the preprint in perpetuity.

It is made available under a CC-BY-ND 4.0 International license .

65. Anastasiou CA, Yannakoulia M, Kontogianni MD, Kosmidis MH, Mamalaki E, Dardiotis E et al. Mediterranean lifestyle in relation to cognitive health: results from the HELIAD study. Nutrients 2018; 10: 1557.

66. Yannakoulia M, Kontogianni M, Scarmeas N. Cognitive health and Mediterranean diet: just diet or lifestyle pattern? Ageing Res Rev 2015; 20: 74-78.

67. Gow AJ, Johnson W, Mishra G, HALCyon Study Team, Richards M, Kuh D et al. Is age kinder to the initially more able? Yes, and no. Intelligence 2012; 40: 49-59.

68. Salthouse TA. Does the direction and magnitude of cognitive change depend on initial level of ability? Intelligence 2012; 40: 352-361.

69. Lövdén M, Fratiglioni L, Glymour MM, Lindenberger U, Tucker-Drob EM. Education and cognitive functioning across the life span. Psychol Sci Public Interest 2020; 21: 6-41.

70. Salthouse TA. Mental exercise and mental aging: Evaluating the validity of the "use it or lose it" hypothesis. Perspect Psychol Sci 2006; 1: 68-87.

71. Salthouse, TA. The processing-speed theory of adult age differences in cognition. Psychol Rev 1996; 103: 403-428.

72. Salthouse, TA, Ferrer-Caja E. What needs to be explained to account for age-related effects on multiple cognitive variables? Psychol Aging 2004; 18: 91-110.

73. Tam HM, Lam CL, Huang H, Wang B, Lee TM. Age-related difference in relationships between cognitive processing speed and general cognitive status. Appl Neuropsychol Adult 2015; 22: 94-99.

74. Nyberg L, Lövdén M, Riklund K, Lindenberger U, Bäckman L. Memory aging and brain maintenance. Trends Cogn Sci 2012; 16: 292-305.

75. Salthouse TA. Influence of age on practice effects in longitudinal neurocognitive change. Neuropsychology. 2010; 24: 563-572.

76. Goh JO, An Y, Resnick SM. Differential trajectories of age-related changes in components of executive and memory processes. Psychol Aging. 2012; 27: 707-719.

77. Schaie KW. (2004). Cognitive aging. In: Technology for adaptive aging. National Academies Press, US, 2004, pp 43-63.

78. Small BJ, Dixon RA, McArdle JJ. Tracking cognition-health changes from 55 to 95 years of age. $J$ Gerontol B Psychol Sci 2011; 66: i153-il61.

79. Marseglia A, Fratiglioni L, Kalpouzos G, Wang R, Bäckman L, Xu W. Prediabetes and diabetes accelerate cognitive decline and predict microvascular lesions: a population-based cohort study. Alzheimers Dement 2019; 15: 25-33.

80. Frisher M, Mendonça M, Shelton N, Pikhart H, de Oliveira C, Holdsworth C. Is alcohol consumption in older adults associated with poor self-rated health? Cross-sectional and longitudinal analyses from the English Longitudinal Study of Ageing. BMC Public Health 2015; 15: 1-9.

81. Anstey KJ, Cherbuin N, Budge M, Young J. Body mass index in midlife and late $\square$ life as a risk factor for dementia: a meta $\square$ analysis of prospective studies. Obes Rev 2011; 12: e426-e437. 
medRxiv preprint doi: https://doi.org/10.1101/2022.02.25.22271448; this version posted February 26, 2022. The copyright holder for this preprint

(which was not certified by peer review) is the author/funder, who has granted medRxiv a license to display the preprint in perpetuity. It is made available under a CC-BY-ND 4.0 International license .

PREDICTORS OF LONGITUDINAL COGNITIVE AGEING...

82. Carroll S, Turkheimer E. Midlife risk factors for late-life cognitive decline. Dev Rev 2018; 48: 201 222.

83. Wagner M, Grodstein F, Proust-Lima C, Samieri C. Long-term trajectories of body weight, diet, and physical activity from midlife through late life and subsequent cognitive decline in women. $\mathrm{Am}$ J Epidemiol 2020; 189: 305-313.

84. Deary IJ. The Stability of Intelligence From Childhood to Old Age. Curr Dir Psychol Sci. 2014; 23: 239-245. 


\section{Box 1 Advantages of the study design}

1. Unusually comprehensive cognitive battery with several high-quality tests for each cognitive domain.

2. 12 year follow-up -5 testing periods-using identical tests, equipment, and testing location.

3. Cognitive testing across an important period from age 70 , when cognitive ageing becomes pertinent, to age 82 , when risk of rapid decline and dementia dramatically increases.

4. Record of general cognitive ability at age 11.

5. Multiple (correlated) candidate determinants are included in mutuallyadjusted models enabling estimates of relative contributions of each predictor to cognitive change.

6. It is well-powered

7. There are sensitivity tests for incident dementia and death 
Table 1. Baseline characteristics of participants overall, and according to completer status and mortality status at the end of follow-up: the Lothian Birth Cohort 1936

\begin{tabular}{|c|c|c|c|c|c|c|c|}
\hline & $\begin{array}{l}\text { All data } \\
(N=1,091)\end{array}$ & $\begin{array}{l}\text { Completers } \\
(\mathrm{N}=431)\end{array}$ & $\begin{array}{l}\text { Non-completers } \\
(\mathrm{N}=660)\end{array}$ & & $\begin{array}{l}\text { Deaths } \\
(N=403)\end{array}$ & $\begin{array}{l}\text { Non-deaths } \\
(N=688)\end{array}$ & \\
\hline Characteristic & $M(S D)$ & $\mathrm{M}(\mathrm{SD})$ & $\mathrm{M}(\mathrm{SD})$ & P-value & $M(S D)$ & $M(S D)$ & P-value \\
\hline Age, yrs & $69.5(0.8)$ & $69.5(0.8)$ & $69.6(0.8)$ & 0.04 & $69.5(0.8)$ & $69.5(0.9)$ & 0.97 \\
\hline Education, yrs & $10.7(1.1)$ & $10.9(1.2)$ & $10.6(1.1)$ & $<0.001$ & $10.7(1.1)$ & $10.8(1.2)$ & 0.09 \\
\hline Age 11 IQ & $100.0(15.0)$ & $102.4(15.0)$ & $98.5(14.8)$ & $<0.001$ & $98.4(15.0)$ & $100.9(14.9)$ & 0.008 \\
\hline Adult SES & $2.4(0.9)$ & $2.3(0.9)$ & $2.5(0.9)$ & $<0.001$ & $2.6(0.9)$ & $2.3(0.9)$ & $<0.001$ \\
\hline Physical activity & $3.0(1.1)$ & $3.2(1.1)$ & $2.9(1.1)$ & $<0.001$ & $2.8(1.2)$ & $3.0(1.0)$ & 0.007 \\
\hline Body mass index & $27.8(4.4)$ & $27.4(4.6)$ & $28.0(4.0)$ & 0.01 & $28.3(4.9)$ & $27.5(4.0)$ & 0.005 \\
\hline Alcohol intake, units & $10.5(14.2)$ & $9.8(11.4)$ & $11.0(15.7)$ & 0.16 & $12.0(18.0)$ & $9.7(11.3)$ & 0.01 \\
\hline \multirow[t]{2}{*}{ Depressive symptoms } & $2.8(2.2)$ & $2.5(2.3)$ & $3.0(2.1)$ & 0.001 & $3.1(2.5)$ & $2.6(2.1)$ & $<0.001$ \\
\hline & $N(\%)$ & $\mathrm{N}(\%)$ & $N(\%)$ & & $N(\%)$ & $N(\%)$ & \\
\hline Female & $543(49.8 \%)$ & $222(51.5 \%)$ & $321(48.6 \%)$ & 0.35 & $170(42.2 \%)$ & $373(54.2 \%)$ & $<0.001$ \\
\hline Lives alone & $266(24.4 \%)$ & $108(25.0 \%)$ & $158(23.9 \%)$ & 0.96 & $113(28.0 \%)$ & $182(26.5 \%)$ & 0.55 \\
\hline Current smoker & $125(11.5 \%)$ & $16(3.7 \%)$ & $109(16.5 \%)$ & $<0.001$ & $86(21.3 \%)$ & $38(5.5 \%)$ & $<0.001$ \\
\hline CVD & $268(24.6 \%)$ & $90(20.9 \%)$ & $178(27.0 \%)$ & 0.02 & $118(29.3 \%)$ & $150(21.8 \%)$ & 0.006 \\
\hline Diabetes & $91(8.3 \%)$ & $20(4.6 \%)$ & $71(10.8 \%)$ & $<0.001$ & $57(14.1 \%)$ & $34(4.9 \%)$ & $<0.001$ \\
\hline Stroke & $54(4.9 \%)$ & $12(2.8 \%)$ & $42(6.4 \%)$ & 0.008 & $33(8.2 \%)$ & $21(3.1 \%)$ & $<0.001$ \\
\hline Cognitive tests & $M(S D)$ & $M(S D)$ & $M(S D)$ & & $M(S D)$ & $M(S D)$ & \\
\hline Block Design & $33.8(10.3)$ & $35.9(10.0)$ & $32.4(10.3)$ & $<0.001$ & $32.1(10.1)$ & $34.8(10.3)$ & $<0.001$ \\
\hline Matrix Reasoning & $13.5(5.1)$ & $14.7(5.0)$ & $12.7(5.1)$ & $<0.001$ & $12.6(5.0)$ & $14.0(5.1)$ & $<0.001$ \\
\hline Spatial Span & $7.4(1.4)$ & $7.6(1.4)$ & $7.2(1.4)$ & $<0.001$ & $7.1(1.4)$ & $7.5(1.4)$ & $<0.001$ \\
\hline Digit-symbol Coding & $56.6(12.9)$ & $60.0(12.0)$ & $54.4(13.0)$ & $<0.001$ & $52.9(13.0)$ & $58.8(12.4)$ & $<0.001$ \\
\hline Symbol Search & $24.7(6.4)$ & $25.9(6.6)$ & $23.9(6.2)$ & $<0.001$ & $23.5(6.5)$ & $25.4(6.2)$ & $<0.001$ \\
\hline Choice Reaction Time & $0.642(0.086)$ & $0.623(0.076)$ & $0.655(0.089)$ & $<0.001$ & $0.659(0.093)$ & $0.632(0.080)$ & $<0.001$ \\
\hline Inspection Time & $112.1(11.0)$ & $114.1(10.0)$ & $110.8(11.5)$ & $<0.001$ & $110.8(11.9)$ & $112.9(10.4)$ & 0.003 \\
\hline Logical Memory & $71.4(17.9)$ & $74.6(17.2)$ & $69.4(18.2)$ & $<0.001$ & $69.7(19.4)$ & $72.5(17.0)$ & 0.013 \\
\hline
\end{tabular}




\begin{tabular}{|l|l|l|l|l|l|l|}
\hline Verbal Pairs & $26.4(9.1)$ & $28.2(8.3)$ & $25.2(9.5)$ & $<0.001$ & $25.9(9.4)$ & 0.120 \\
\hline Digits Backwards & $7.7(2.3)$ & $8.1(2.4)$ & $7.5(2.2)$ & $<0.001$ & $7.5(2.1)$ & $26.8(9.0)$ \\
\hline NART & $34.5(8.2)$ & $35.7(7.8)$ & $33.7(8.3)$ & $<0.001$ & $33.7(8.3)$ & $3.9(2.3)$ \\
\hline WTAR & $41.0(7.2)$ & $42.2(6.7)$ & $40.3(7.4)$ & $<0.001$ & $40.1(7.3)$ & 0.005 \\
\hline Verbal Fluency & $42.4(12.5)$ & $43.6(12.5)$ & $41.7(12.5)$ & 0.01 & $41.5(13.0)$ & $41.6(7.0)$ \\
\hline
\end{tabular}

Note: SES, socio-economic status; CVD, cardiovascular disease.

Adult SES (classes 1-5) is scored negatively where class $1=$ most professional and class $5=$ manual.

Completers were those participants who remained in the study through waves 1 (age 70 years) to wave 5 (age 82 years). Non-completers include participants who died or withdrew from the study at any point across waves 1 to 5 .

Mortality data is correct as of April 2021.

P-values derived from one-way ANOVA or Chi-square tests as appropriate. 
Table 2. Longitudinal cognitive test scores for all participants

\begin{tabular}{|c|c|c|c|c|c|c|c|c|c|c|}
\hline \multirow[b]{3}{*}{ Cognitive test } & \multicolumn{2}{|c|}{70 years } & \multirow{2}{*}{\multicolumn{2}{|c|}{$\begin{array}{l}73 \text { years } \\
\text { Attrition } 20.6 \%\end{array}$}} & \multirow{2}{*}{\multicolumn{2}{|c|}{$\begin{array}{l}76 \text { years } \\
\text { Attrition } 19.5 \%\end{array}$}} & \multirow{2}{*}{\multicolumn{2}{|c|}{$\begin{array}{l}79 \text { years } \\
\text { Attrition } 21.1 \%\end{array}$}} & \multirow{2}{*}{\multicolumn{2}{|c|}{$\begin{array}{l}82 \text { years } \\
\text { Attrition } 21.6 \%\end{array}$}} \\
\hline & \multirow[b]{2}{*}{$\mathrm{N}$} & \multirow[b]{2}{*}{$M(S D)$} & & & & & & & & \\
\hline & & & $\mathrm{N}$ & $M(S D)$ & $\mathrm{N}$ & $M(S D)$ & $\mathrm{N}$ & $M(S D)$ & $\mathrm{N}$ & $M(S D)$ \\
\hline Block Design & 1085 & $33.8(10.3)$ & 864 & $33.6(10.1)$ & 691 & $32.2(9.9)$ & 535 & $31.2(9.6)$ & 420 & $29.9(9.6)$ \\
\hline Matrix Reasoning & 1086 & $13.5(5.1)$ & 863 & $13.2(5.0)$ & 689 & $13.0(4.9)$ & 535 & $12.9(5.0)$ & 418 & $12.9(5.2)$ \\
\hline Spatial Span & 1084 & $7.4(1.4)$ & 861 & $7.3(1.4)$ & 690 & $7.3(1.4)$ & 536 & $7.1(1.4)$ & 421 & $6.9(1.4)$ \\
\hline Digit-symbol Coding & 1086 & $56.6(12.9)$ & 862 & $56.4(12.3)$ & 685 & $53.8(12.9)$ & 535 & $51.2(13.0)$ & 418 & $51.0(12.8)$ \\
\hline Symbol Search & 1086 & $24.7(6.4)$ & 862 & $24.6(6.2)$ & 687 & $24.6(6.5)$ & 531 & $22.7(6.7)$ & 415 & $22.2(6.9)$ \\
\hline Choice Reaction Time (secs) & 1084 & $0.642(0.086)$ & 865 & $0.649(0.090)$ & 685 & $0.679(0.102)$ & 543 & $0.706(0.114)$ & 423 & $0.722(0.120)$ \\
\hline Inspection Time & 1041 & $112.1(11.0)$ & 838 & $111.2(11.8)$ & 654 & $110.1(12.5)$ & 465 & $106.7(13.6)$ & 382 & $106.0(12.7)$ \\
\hline Logical Memory & 1087 & $71.4(17.9)$ & 864 & $74.3(17.9)$ & 688 & $74.6(19.2)$ & 542 & $72.7(20.4)$ & 423 & $72.1(21.5)$ \\
\hline Verbal Pairs & 1050 & $26.4(9.1)$ & 843 & $27.2(9.5)$ & 663 & $26.4(9.6)$ & 497 & $27.1(9.6)$ & 380 & $27.4(9.5)$ \\
\hline Digits Backwards & 1090 & $7.7(2.3)$ & 866 & $7.8(2.3)$ & 695 & $7.8(2.4)$ & 548 & $7.6(2.2)$ & 426 & $7.2(2.3)$ \\
\hline NART & 1089 & $34.5(8.2)$ & 864 & $34.4(8.2)$ & 695 & $35.0(8.0)$ & 546 & $35.6(8.2)$ & 426 & $36.1(7.8)$ \\
\hline WTAR & 1089 & $41.0(7.2)$ & 864 & $41.0(7.0)$ & 694 & $41.1(7.0)$ & 546 & $41.6(7.0)$ & 426 & $42.2(6.6)$ \\
\hline Verbal Fluency & 1087 & $42.4(12.5)$ & 865 & $43.2(12.9)$ & 696 & $42.9(12.8)$ & 547 & $43.6(13.3)$ & 426 & $43.6(12.7)$ \\
\hline
\end{tabular}

Note: NART, National Adult Reading Test; WTAR, Wechsler Test of Adult Reading.

Ns at each wave were 1,091 (70 years), 866 ( 73 years), 697 (76 years), 550 (79 years), and 431 (82 years).

All tests are positively scored (i.e. higher scores = better performance) with the exception of Choice Reaction Time (in seconds) which is negatively scored (i.e. higher scores $=$ slower performance). 
Table 3. Latent growth curve models: unstandardized means and variances for the intercept and slope of each cognitive domain, and by APOEe4 carrier status (slopes refer to change from age 70 to age 82 )

\begin{tabular}{|c|c|c|c|c|c|c|}
\hline \multirow[b]{2}{*}{ Cognitive domain } & \multicolumn{2}{|l|}{ Intercepts } & \multicolumn{2}{|l|}{ Slopes } & \multicolumn{2}{|c|}{ SD change in each domain } \\
\hline & Mean (SE) & Variance (SE) & Mean (SE) & Variance (SE) & SD change/yr & Rank order of SD change \\
\hline \multicolumn{7}{|l|}{ All participants } \\
\hline Visuospatial & $15.888(0.759)^{* * *}$ & $13.711(1.021)$ & $-0.201(0.059)^{* *}$ & $0.015(0.006)$ & -0.054 & 2 \\
\hline Processing speed & $97.982(6.013)^{* * *}$ & $21.971(1.479)$ & $-0.413(0.046)^{* * *}$ & $0.084(0.012)$ & -0.088 & 1 \\
\hline Memory & $72.889(0.534)^{* * *}$ & $171.046(17.209)$ & $-0.361(0.066)^{* * *}$ & $1.722(0.167)$ & -0.028 & 3 \\
\hline Verbal ability & $46.757(1.090)^{* * *}$ & $59.634(3.009)$ & $-0.022(0.010)^{*}$ & $0.016(0.004)$ & -0.003 & 4 \\
\hline \multicolumn{7}{|c|}{ APOEe4 non-carriers } \\
\hline Visuospatial & $16.265(1.053)^{* * *}$ & $13.879(1.308)$ & $-0.125(0.048)^{* *}$ & $0.008(0.005)$ & -0.033 & 2 \\
\hline Processing speed & $102.548(7.618)^{* * *}$ & $21.758(1.760)$ & $-0.318(0.050)^{* * *}$ & $0.046(0.010)$ & -0.068 & 1 \\
\hline Memory & $73.074(0.653)^{* * *}$ & $182.660(20.679)$ & $-0.135(0.072)^{\mathrm{NS}}$ & $1.235(0.155)$ & -0.010 & 3 \\
\hline Verbal ability & $46.607(1.373)^{*}$ & $58.104(3.691)$ & $-0.026(0.017)^{\mathrm{NS}}$ & $0.019(0.005)$ & -0.004 & 4 \\
\hline \multicolumn{7}{|l|}{ APOEe4 carriers } \\
\hline Visuospatial & $14.657(1.216)^{* * *}$ & $12.850(1.739)$ & $-0.232(0.081)^{* *}$ & $0.022(0.011)$ & -0.065 & 3 \\
\hline Processing speed & $93.361(12.045)^{* * *}$ & $22.652(2.981)$ & $-0.504(0.084)^{* * *}$ & $0.167(0.036)$ & -0.106 & 1 \\
\hline Memory & $71.918(1.033)^{* * *}$ & $160.519(35.897)$ & $-0.918(0.148)^{* * *}$ & $2.714(0.463)$ & -0.072 & 2 \\
\hline Verbal ability & $46.416(2.036)^{* * *}$ & $63.869(6.017)$ & $-0.021(0.015)^{\mathrm{NS}}$ & $0.015(0.007)$ & -0.003 & 4 \\
\hline
\end{tabular}

Note: SE, standard error.

Models were run separately for each domain.

Path weights for calculation of the slope factor: Baseline=0; to $w 2=2.98$; to $w 3=6.75$; to $w 4=9.81$; to $w 5=12.53$

$\mathrm{SD}$ chan ge/yr is the slope mean divided by the intercept standard deviation; rank order of SD change is from highest (1=most change) to lowest (13=least change)

Model fit statistics are given in Supplementary Table S4

${ }^{*} \mathrm{p}<0.05 ; * * \mathrm{p}<0.01 ; * * * \mathrm{p}<0.001$ 
Table 4. Latent growth curve models: predictors of intercepts (age 70) and slopes of change (age 70 to 82) where predictors are entered simultaneously (standardised coefficients (Estimate), standard errors (SE), and P-values)

\begin{tabular}{|c|c|c|c|c|c|c|c|c|c|c|}
\hline \multirow[b]{2}{*}{ Predictors } & \multicolumn{2}{|l|}{ Visuospatial ability } & \multicolumn{2}{|l|}{ Processing speed } & \multicolumn{2}{|l|}{ Memory } & \multicolumn{2}{|l|}{ Verbal ability } & \multicolumn{2}{|c|}{ General cognitive function } \\
\hline & Estimate (SE) & $P$ values & Estimate (SE) & $P$ values & Estimate (SE) & $P$ values & Estimate (SE) & $P$ values & Estimate (SE) & $P$ values \\
\hline \multicolumn{11}{|l|}{ Intercept on } \\
\hline $\mathrm{Age}^{-}$ & $-0.110(0.027)$ & $<0.001$ & $-0.149(0.027)$ & $<0.001$ & $-0.157(0.030)$ & $<0.001$ & $-0.089(0.020)$ & $<0.001$ & $-0.140(0.021)$ & $<0.001$ \\
\hline Sex & $-0.261(0.029)$ & $<0.001$ & $-0.022(0.031)$ & 0.47 & $0.121(0.033)$ & $<0.001$ & $0.002(0.022)$ & 0.92 & $-0.042(0.023)$ & 0.07 \\
\hline Age $11 \mathrm{IQ}^{+}$ & $0.494(0.028)$ & $<0.001$ & $0.442(0.029)$ & $<0.001$ & $0.561(0.033)$ & $<0.001$ & $0.566(0.020)$ & $<0.001$ & $0.668(0.020)$ & $<0.001$ \\
\hline Education $^{+}$ & $0.109(0.032)$ & 0.001 & $0.031(0.033)$ & 0.35 & $0.157(0.036)$ & $<0.001$ & $0.239(0.023)$ & $<0.001$ & $0.197(0.025)$ & $<0.001$ \\
\hline Adult SES ${ }^{-}$ & $-0.124(0.032)$ & $<0.001$ & $-0.137(0.032)$ & $<0.001$ & $0.015(0.036)$ & 0.69 & $-0.110(0.024)$ & $<0.001$ & $-0.120(0.025)$ & $<0.001$ \\
\hline Lives alone $^{-}$ & $0.029(0.028)$ & 0.30 & $-0.003(0.028)$ & 0.91 & $0.021(0.031)$ & 0.50 & $-0.033(0.021)$ & 0.11 & $-0.007(0.021)$ & 0.74 \\
\hline Smoking category $^{-}$ & $-0.065(0.028)$ & 0.02 & $-0.095(0.028)$ & 0.001 & $0.008(0.031)$ & 0.80 & $-0.032(0.021)$ & 0.12 & $-0.026(0.022)$ & 0.24 \\
\hline Physical activity $^{+}$ & $0.039(0.030)$ & 0.20 & $0.082(0.031)$ & 0.009 & $0.044(0.034)$ & 0.20 & $-0.009(0.023)$ & 0.40 & $0.035(0.024)$ & 0.14 \\
\hline Body mass index ${ }^{-}$ & $0.084(0.028)$ & 0.003 & $0.051(0.031)$ & 0.08 & $0.066(0.032)$ & 0.03 & $-0.053(0.021)$ & 0.01 & $0.015(0.022)$ & 0.50 \\
\hline Alcohol units, week $^{+}$ & $0.000(0.029)$ & 0.98 & $-0.015(0.047)$ & 0.74 & $0.036(0.032)$ & 0.26 & $-0.019(0.021)$ & 0.37 & $-0.011(0.022)$ & 0.61 \\
\hline APOEe4 $^{-}$ & $-0.100(0.028)$ & $<0.001$ & $-0.103(0.028)$ & $<0.001$ & $-0.038(0.031)$ & 0.23 & $0.001(0.021)$ & 0.96 & $-0.056(0.022)$ & 0.009 \\
\hline Depressive symptoms $^{-}$ & $-0.059(0.028)$ & 0.03 & $-0.101(0.028)$ & $<0.001$ & $-0.072(0.031)$ & 0.02 & $-0.018(0.021)$ & 0.38 & $-0.066(0.022)$ & 0.002 \\
\hline $\mathrm{CVD}^{-}$ & $-0.034(0.028)$ & 0.22 & $-0.069(0.028)$ & 0.013 & $0.043(0.031)$ & 0.17 & $0.013(0.020)$ & 0.52 & $-0.005(0.021)$ & 0.80 \\
\hline Diabetes $^{-}$ & $-0.057(0.028)$ & 0.04 & $-0.057(0.028)$ & 0.04 & $-0.005(0.031)$ & 0.88 & $-0.053(0.021)$ & 0.01 & $-0.055(0.021)$ & 0.01 \\
\hline Stroke $^{-}$ & $-0.024(0.028)$ & 0.39 & $-0.071(0.028)$ & 0.011 & $0.047(0.031)$ & 0.12 & $0.028(0.020)$ & 0.18 & $0.002(0.021)$ & 0.93 \\
\hline \multicolumn{11}{|l|}{ Slope on } \\
\hline $\mathrm{Age}^{-}$ & $0.111(0.062)$ & 0.08 & $0.029(0.054)$ & 0.59 & $-0.005(0.044)$ & 0.91 & $0.262(0.069)$ & $<0.001$ & $0.039(0.041)$ & 0.34 \\
\hline Sex & $0.028(0.067)$ & 0.68 & $0.075(0.050)$ & 0.13 & $0.037(0.048)$ & 0.44 & $0.083(0.066)$ & 0.21 & $0.040(0.044)$ & 0.37 \\
\hline Age $11 \mathrm{IQ}^{+}$ & $-0.272(0.077)$ & $<0.001$ & $-0.044(0.057)$ & 0.44 & $-0.027(0.050)$ & 0.59 & $0.111(0.070)$ & 0.11 & $-0.062(0.046)$ & 0.18 \\
\hline Education $^{+}$ & $-0.094(0.072)$ & 0.19 & $0.011(0.058)$ & 0.85 & $-0.027(0.050)$ & 0.59 & $-0.161(0.073)$ & 0.03 & $-0.057(0.047)$ & 0.23 \\
\hline Adult SES ${ }^{-}$ & $-0.092(0.072)$ & 0.20 & $0.025(0.059)$ & 0.67 & $-0.043(0.051)$ & 0.40 & $-0.020(0.069)$ & 0.77 & $-0.010(0.047)$ & 0.83 \\
\hline Lives alone $^{-}$ & $-0.119(0.065)$ & 0.07 & $-0.037(0.046)$ & 0.43 & $-0.051(0.045)$ & 0.26 & $0.014(0.062)$ & 0.83 & $-0.031(0.042)$ & 0.45 \\
\hline Smoking category $^{-}$ & $-0.125(0.072)$ & 0.08 & $0.022(0.049)$ & 0.65 & $0.030(0.049)$ & 0.53 & $-0.192(0.070)$ & 0.007 & $-0.021(0.044)$ & 0.63 \\
\hline Physical activity $^{+}$ & $0.047(0.068)$ & 0.49 & $0.020(0.055)$ & 0.76 & $0.006(0.050)$ & 0.91 & $0.049(0.069)$ & 0.47 & $0.062(0.046)$ & 0.17 \\
\hline Body mass index & $-0.092(0.067)$ & 0.17 & $-0.073(0.055)$ & 0.18 & $-0.021(0.047)$ & 0.66 & $-0.004(0.064)$ & 0.95 & $-0.036(0.042)$ & 0.39 \\
\hline Alcohol units, week $^{+}$ & $-0.146(0.074)$ & 0.048 & $0.019(0.057)$ & 0.74 & $-0.047(0.050)$ & 0.35 & $0.046(0.071)$ & 0.51 & $-0.015(0.045)$ & 0.73 \\
\hline APOEe4 $^{-}$ & $-0.170(0.065)$ & 0.009 & $-0.211(0.047)$ & $<0.001$ & $-0.234(0.044)$ & $<0.001$ & $-0.058(0.061)$ & 0.35 & $-0.246(0.039)$ & $<0.001$ \\
\hline Depressive symptoms ${ }^{-}$ & $-0.100(0.065)$ & 0.12 & $-0.060(0.055)$ & 0.27 & $0.013(0.046)$ & 0.78 & $-0.096(0.063)$ & 0.13 & $-0.071(0.042)$ & 0.09 \\
\hline $\mathrm{CVD}^{-}$ & $-0.064(0.064)$ & 0.32 & $-0.048(0.046)$ & 0.30 & $0.005(0.046)$ & 0.90 & $-0.060(0.063)$ & 0.34 & $-0.053(0.042)$ & 0.21 \\
\hline Diabetes $^{-}$ & $-0.012(0.072)$ & 0.87 & $-0.040(0.050)$ & 0.42 & $-0.088(0.050)$ & 0.08 & $-0.008(0.071)$ & 0.91 & $-0.043(0.044)$ & 0.33 \\
\hline Stroke ${ }^{-}$ & $0.012(0.074)$ & 0.87 & $0.083(0.051)$ & 0.10 & $0.027(0.051)$ & 0.60 & $-0.071(0.071)$ & 0.32 & $0.039(0.045)$ & 0.40 \\
\hline
\end{tabular}

Note: SE, standard error; SES, socio-economic status; CVD, cardiovascular disease

'hypothesized to have a positive association with cognitive function; ${ }^{-}$hypothesized to have a negative association with cognitive function. 
Model estimates are fully standardised.

Path weights for calculation of the slope factor: Baseline $=0$; to $w 2=2.98$; to $w 3=6.75$; to $w 4=9.81$; to $w 5=12.53$

Models were run separately for each domain; general cognitive function is based on the intercepts and slopes of the four cognitive domains

Boldtype indicates statistical significance following FDR (false discovery rate) correction 


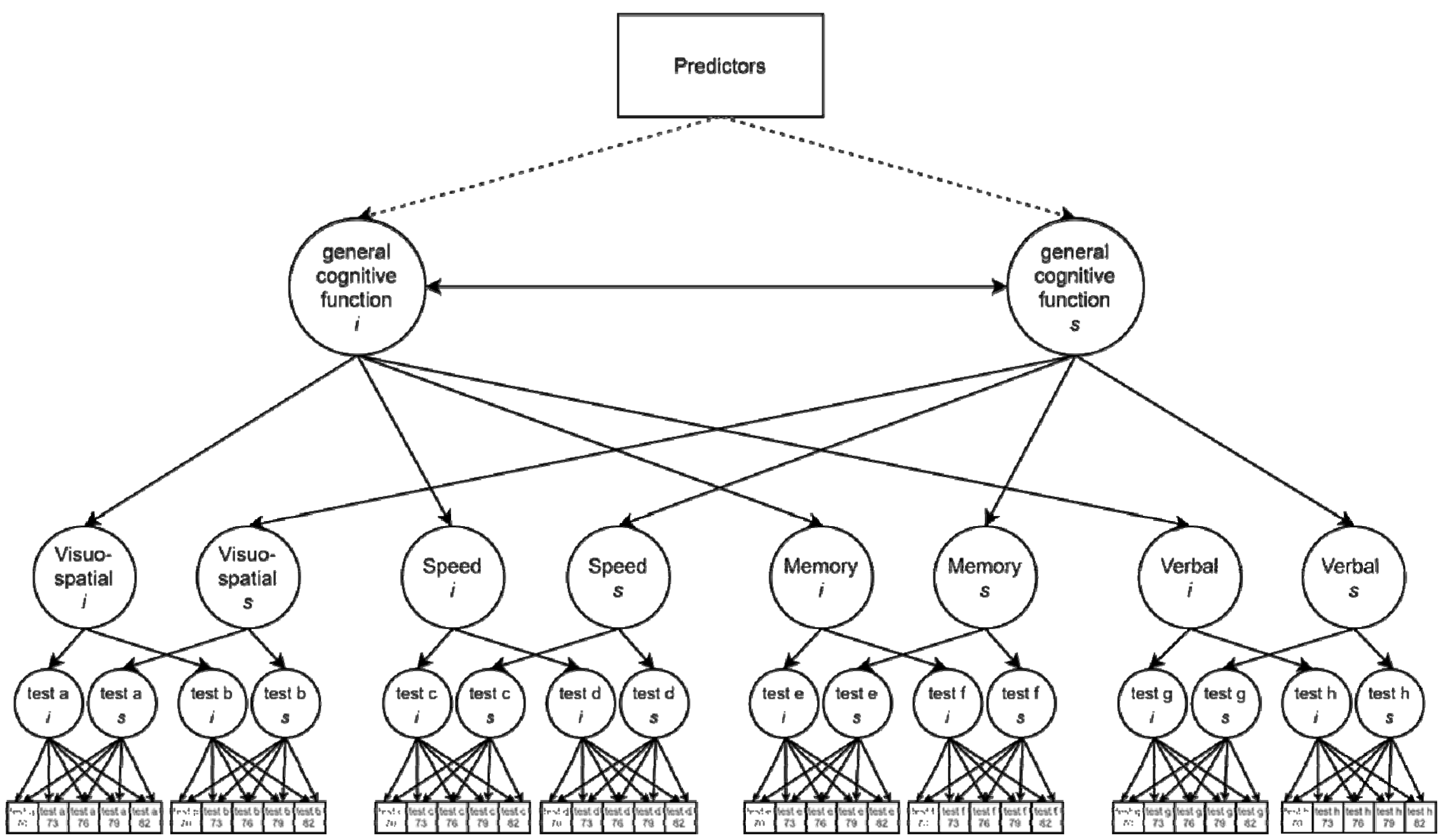

Figure 1. Schematic latent growth curve model in which predictors are associated with the intercept and slope of a latent factor of general cognitive function. A latent growth curve was estimated across five waves of data in a hierarchical model based on the intercepts and slopes of four cognitive domains. For illustrative purposes, not all tests are shown. The regressions of predictors (represented by the dotted lines) on general cognitive function intercept ( $i$ ) and slope $(s)$ were the associations of interest. Note that separate models were run for each of the four cognitive domains where the regressions on 'domain' intercept $(i)$ and slope $(s)$ were the associations of interest. 

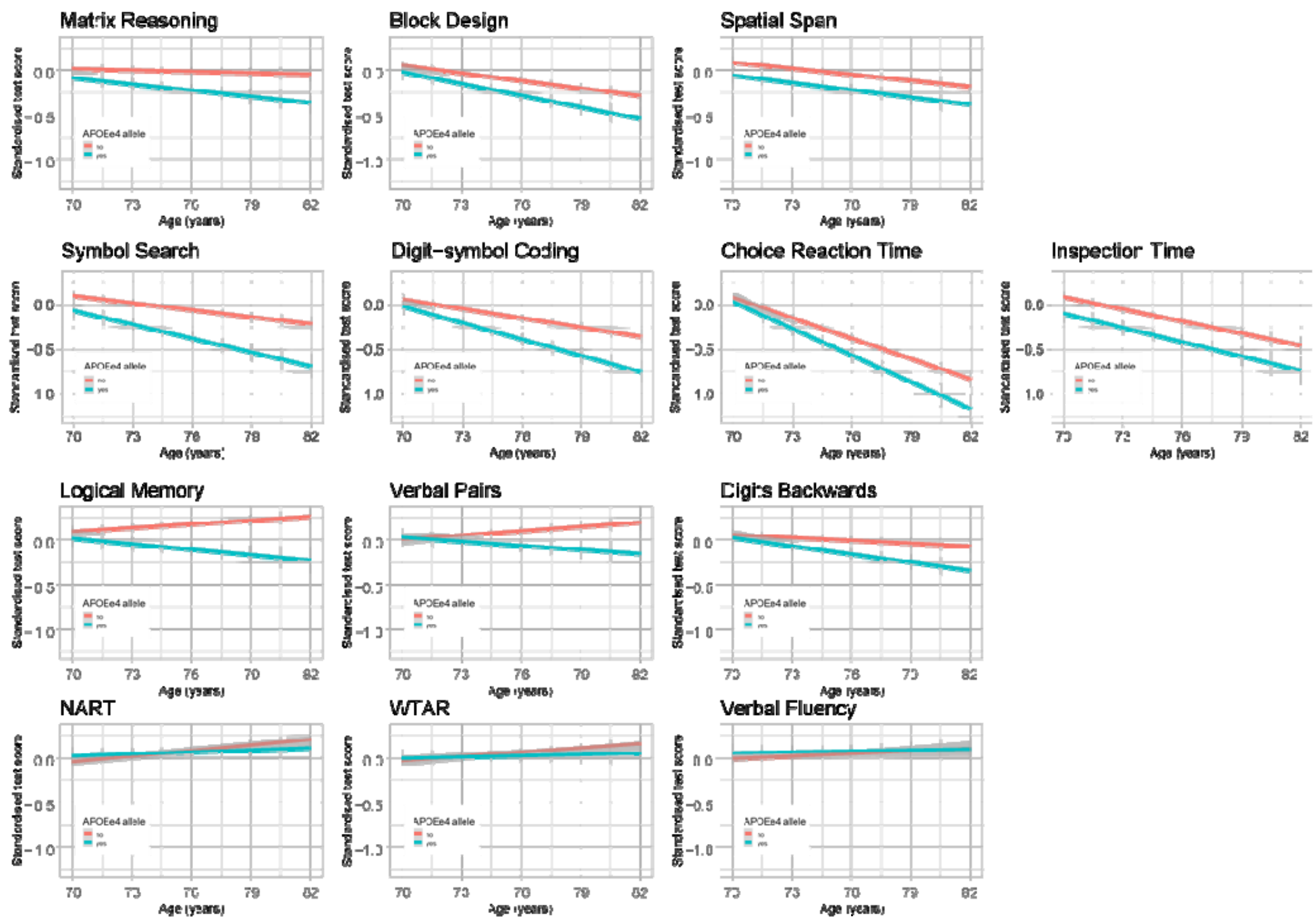

Figure 2. Plots of the regression lines fitted through the raw data, normalised for baseline score, to illustrate the differences in trajectories of cognitive change with age by APOEe4 carrier status (with shaded $95 \%$ confidence intervals). Red $=$ non-carrier, blue $=$ carrier. 
PREDICTORS OF LONGITUDINAL COGNITIVE AGEING...

\section{a) Cognitive Tests}

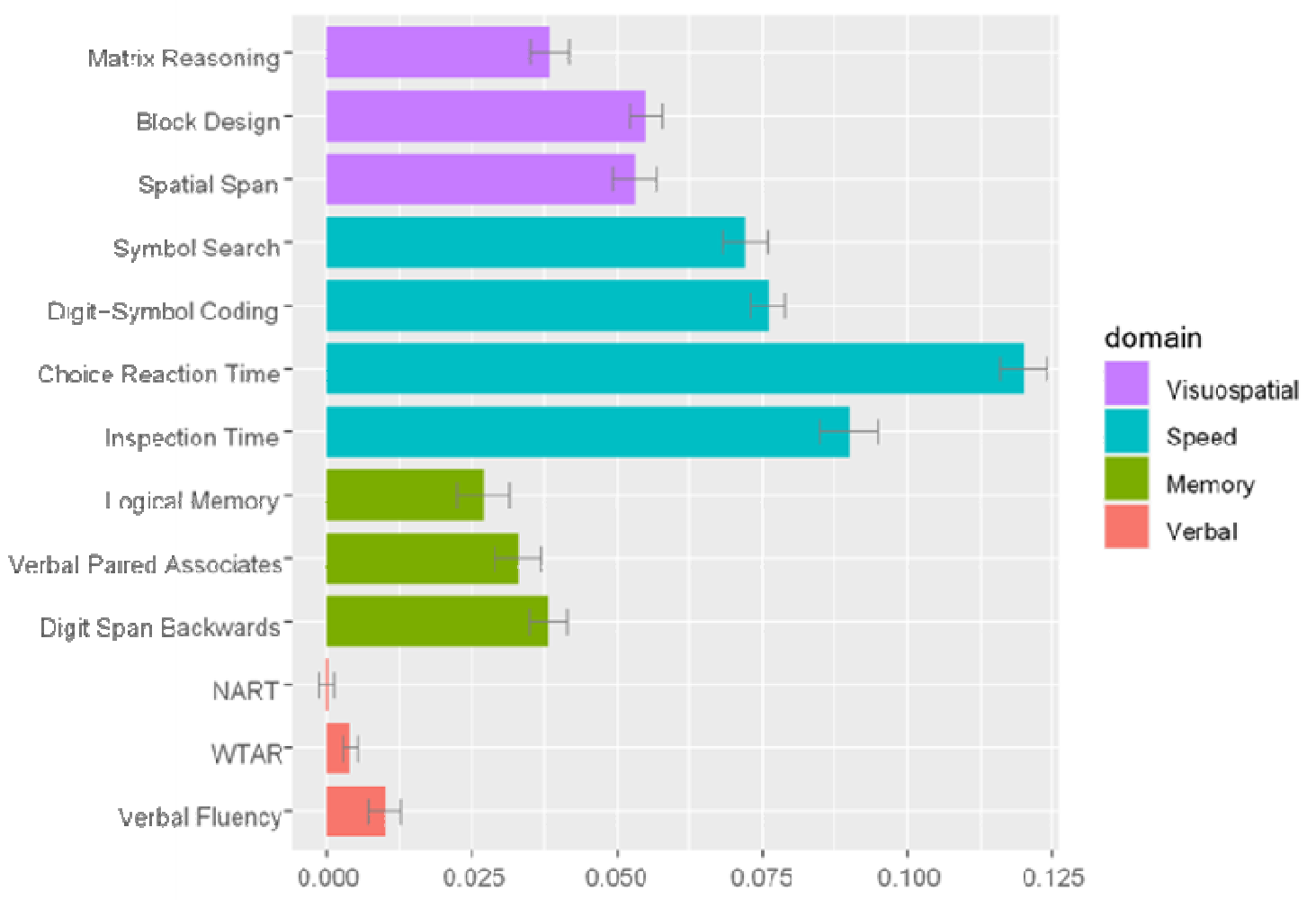

31

\section{b) Cognitive Domains}

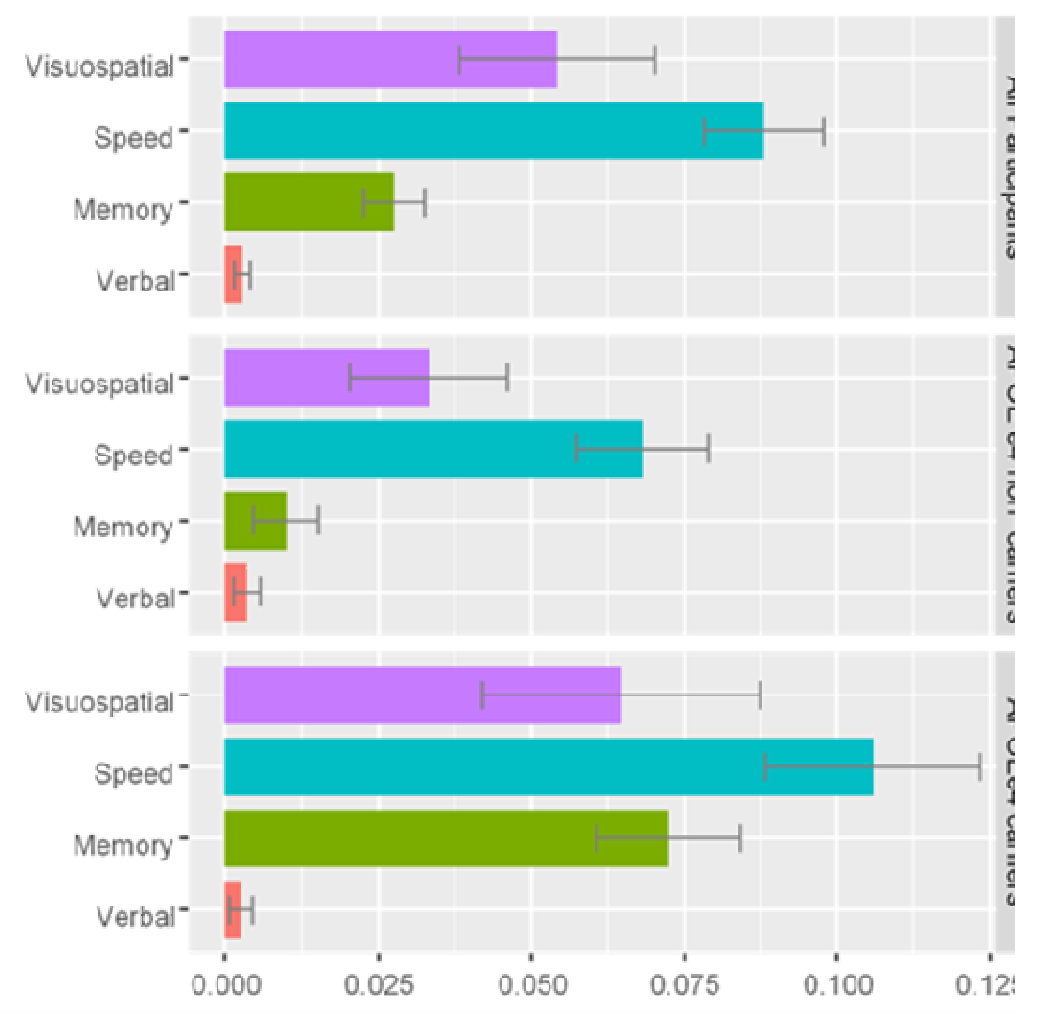

Figure 3. Standard deviation (SD) change per year in a) each cognitive test (grouped by cognitive domain), and b) each cognitive domain (grouped by all participants, and by APOE e4 non-carriers and carriers). SD change per year was derived from latent growth curve models, by calculating the slope mean divided by the intercept SD. SD change per year was converted to +ve values for illustrative purposes, with the exception of NART (National Adult Reading Test) which became -ve. Error bars represent the standard error of SD change per year. 
PREDICTORS OF LONGITUDINAL COGNITIVE AGEING...

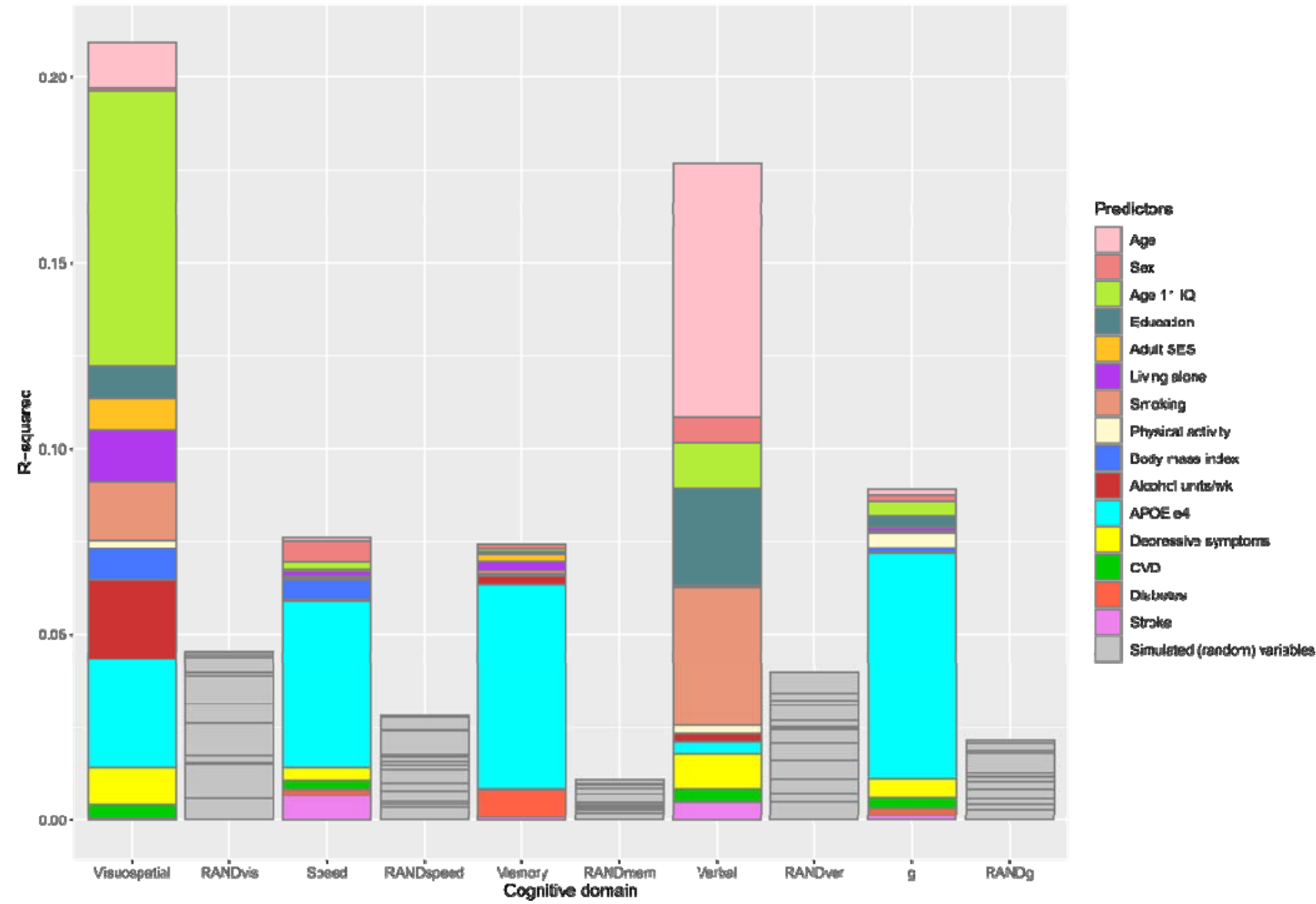

Figure 4. Stacked barplots showing the unique variance $\left(R^{2}\right)$ in cognitive domain slopes explained by the predictor variables in the multivariate models (Table 5). Grey columns show the $R^{2}$ explained by the same number of simulated (random) variables in each cognitive domain as a comparison. 